\title{
Ranbp2 haploinsufficiency mediates distinct cellular and biochemical phenotypes in brain and retinal dopaminergic and glia cells elicited by the Parkinsonian neurotoxin, 1-methyl-4- phenyl-1,2,3,6-tetrahydropyridine (MPTP)
}

\author{
Kyoung-in Cho $\cdot$ Kelly Searle $\cdot$ Mason Webb • \\ Haiqing Yi • Paulo A. Ferreira
}

Received: 30 March 2012/Revised: 4 June 2012/ Accepted: 21 June 2012/Published online: 21 July 2012

(C) The Author(s) 2012. This article is published with open access at Springerlink.com

\begin{abstract}
Many components and pathways transducing multifaceted and deleterious effects of stress stimuli remain ill-defined. The Ran-binding protein 2 (RanBP2) interactome modulates the expression of a range of clinical and cell-context-dependent manifestations upon a variety of stressors. We examined the role of Ranbp2 haploinsufficiency on cellular and metabolic manifestations linked to tyrosine-hydroxylase $\left(\mathrm{TH}^{+}\right)$dopaminergic neurons and glial cells of the brain and retina upon acute challenge to 1-methyl-4-phenyl-1,2,3,6-tetrahydropyridine (MPTP), a parkinsonian neurotoxin, which models facets of Parkinson disease. MPTP led to stronger akinetic parkinsonism and slower recovery in Ranbp $2^{+-}$than wild-type mice without viability changes of brain $\mathrm{TH}^{+}$-neurons of either genotype, with the exception of transient nuclear atypia via changes in chromatin condensation of Ranbp $2^{+/-} \mathrm{TH}^{+}$-neurons. Conversely, the number of wild-type retinal $\mathrm{TH}^{+}$-amacrine
\end{abstract}

M. Webb and K. Searle contributed equally to this work.

Electronic supplementary material The online version of this article (doi:10.1007/s00018-012-1071-9) contains supplementary material, which is available to authorized users.

K. Cho $\cdot$ K. Searle $\cdot$ M. Webb · H. Yi · P. A. Ferreira $(\square)$

Department of Ophthalmology, Duke University Medical

Center, DUEC 3802, 2351 Erwin Road, Durham,

NC 27710, USA

e-mail: paulo.ferreira@duke.edu

K. Searle

Department of Epidemiology, The Johns Hopkins Bloomberg

School of Public Health, 615 N. Wolfe Street,

Baltimore 21205, MD

P. A. Ferreira

Department of Pathology, Duke University Medical Center,

Durham, NC 27710, USA neurons compared to Ranbp $2^{+/-}$underwent milder declines without apoptosis followed by stronger recoveries without neurogenesis. These phenotypes were accompanied by a stronger rise of $\mathrm{EdU}^{+}$-proliferative cells and non-proliferative gliosis of $\mathrm{GFAP}^{+}$-Müller cells in wild-type than Ranbp $^{+/-}$that outlasted the MPTP-insult. Finally, MPTPtreated wild-type and Ranbp2 $2^{+/-}$mice present distinct metabolic footprints in the brain or selective regions thereof, such as striatum, that are supportive of RanBP2-mediated regulation of interdependent metabolic pathways of lysine, cholesterol, free-fatty acids, or their $\beta$-oxidation. These studies demonstrate contrasting gene-environment phenodeviances and roles of Ranbp 2 between dopaminergic and glial cells of the brain and retina upon oxidative stresselicited signaling and factors triggering a continuum of metabolic and cellular manifestations and proxies linked to oxidative stress, and chorioretinal and neurological disorders such as Parkinson.

Keywords Ran-binding protein 2 (RanBP2) . MPTP neurotoxicity · Dopaminergic neurons · Gliosis . Metabolomics · Parkinson · Gene-environment interaction

\section{Introduction}

1-methyl-4-phenyl-1,2,3,6-tetrahydropyridine (MPTP) is a neurotoxin that models multiple facets of Parkinson's disease (PD) [1-4]. 1-methyl-4-phenylpyridinium $\left(\mathrm{MPP}^{+}\right)$is the active metabolite of MPTP that is taken up by dopaminergic neurons [5], where it is thought to poison these by inhibition of the mitochondrial complex I and generation of superoxide anions [6,7]. Previous experiments with mesencephalic neuronal cultures also supported that MPTP could promote the displacement of dopamine from vesicular 
stores, leading then to the intracellular and extracellular auto-oxidation of dopamine and production of reactive oxygen species (ROS) [8]. The pathophysiological relevance of these results are controversial, because (i) dopaminergic neurons (DA) of mice lacking functional Ndufs4, a subunit critical to the functional assembly of complex I, are not protected to $\mathrm{MPP}^{+}$[9] and (ii) acute administration of MPTP still induces neurotoxicity in DA neurons of DA-deficient mice [10], whereas overexpression of the dopamine transporter in striatal neurons of transgenic mice lent support to the concept that impairment of intracellular dopamine vesicular sequestration suffices to promote neurodegeneration [11]. In addition to DA neuronal degeneration, MPTP is also reported to induce gliosis and microglial activation, events that are thought to contribute to the injury of DA neurons $[12,13]$. The effects of MPTP and comparison of its pathophysiological outcomes become more complex with the observations that rodents are more resistant to MPTP neurotoxicity than primates and the multivariate susceptibilities to MPTP treatment vary significantly with mouse strains, sex, age, and treatment modalities [12, 14-20].

The neuroretina also harbors $\mathrm{TH}^{+}$-amacrine neurons. These DA neurons are the least numerous and the largest neurons in the retina because of the large arborization fields they present $[21,22]$. Dopamine plays a role in light adaptation and PD patients suffer from various visual impairments $[23,24]$. MPTP treatment is also reported to reduce reversibly or have no effect on the number of DA amacrine neurons and these effects are accompanied by a decrease of the retinal oscillatory potentials and activation of glial and microglial cells and astrocytes [25-30]. Hence, collectively these results support that the multifaceted and cell-context-dependent responses elicited by the Parkinsonian neurotoxin, MPTP, are susceptible to modulation by ill-characterized factors. Identification and characterization of such biological factors are of considerable therapeutic value, because among other reasons they may uncover disease-relevant pathways and serve as pharmacological targets to promote neuroprotection.

The Ran-binding protein 2 (RanBP2) is known to modulate directly responses elicited by various deleterious stressors, such as phototoxicity [31, 32], infectious agents [33], and carcinogens [34]. In this regard, haploinsufficiency of Ranbp 2 confers neuroprotection to photoreceptor neurons upon light-elicited oxidative stress [31, 32], whereas semidominant mutations in human $R A N B P 2$ promote the rampant necrosis of basal ganglia neurons triggered by febrile states and viral infections of multiple etiologies [33]. Additionally, haploinsufficiency or hypomorphism of Ranbp 2 increases the susceptibility to tumorigenesis in the presence of carcinogens [34]. Parkin, whose loss-of-function causes PD in the human, is reported to associate with RanBP2 [35]. Like Ranbp2, parkin $(P A R K 2)$ is also a tumor-suppressor gene [36]. Parkin and RanBP2 exhibit E3-ubiquitin ligase activity and the association of parkin with RanBP2 promotes the ubiquitination and degradation of RanBP2 [35, 37, 38]. Among other locations, RanBP2 and parkin appear to localize to the mitochondria, where parkin is thought to exert a neuroprotective role [39-42]. arkin $^{-/-}$mice present deficits in lipid and glucose metabolism and energy homeostasis [42, 43], a phenotype that evokes manifestations observed with haploinsufficiency of Ranbp2 [31, 40]. Hence, these data collectively support that RanBP2 modulates stress signaling pathways critical to neuronal viability and that RanBP2 and parkin may share pathomechanisms of relevance to the survival or function of dopaminergic neurons. To further define the role of deficits in RanBP2 in stress-mediated responses, we explored in this study the role of haploinsufficiency of Ranbp 2 in brain and retinal tyrosine-hydroxylase $\left(\mathrm{TH}^{+}\right)$neurons and glial cells upon acute exposure to the Parkinsonian neurotoxin, MPTP, in an inbred mouse strain (129P2/ OlaHsd). We found significant multifaceted phenotypic and metabolic footprint manifestations in the brain and retina between inbred wild-type and Ranbp $2^{+/-}$mice. These phenotypic outcomes may underlie phenodeviances and pathobiological processes shared by diseases linked to oxidative stress, including parkinsonian manifestations.

\section{Materials and methods}

Mice and drug administration

Animal protocols were approved by the Institutional Animal Care and Use Committee at Duke University and the procedures adhered to the ARVO guidelines for the Use of Animals in Vision Research and National Academy of Sciences. Twenty-four to 28-week-old wild-type or Ran$b p 2^{+/-}\left(\right.$Ranbp2 $\left.2^{+/ G t(p G T 0 p f s) 630 W c s}\right)$ male mice previously generated with an identical inbred 129P2/OlaHsd genetic background were employed [40]. Mice were housed in a temperature-controlled and pathogen-free transgenic barrier facility in a standard $12: 12 \mathrm{~h}$ light-dark cycle at $<70$ lux and given ad libitum access to water and breeder chow diet 5LJ5 (Purina). Mice received four bolus i.p. injections of MPTP $\mathrm{HCl}$ (20 mg/kg, Sigma) in physiological saline at 2-h intervals and the first injection was administered 9:00-10:00 a.m. Mice were kept in isolation until being killed. For these studies, all mice were killed by cervical dislocation followed by decapitation at either 6 or 14 days after MPTP treatment.

\section{Open-field test}

Mice were transferred separately to a $46 \times 42 \mathrm{~cm}$ Plexiglas box with the bottom marked with a 25 -square grid. 
Mice motility was recorded daily in isolation for $15 \mathrm{~min}$; data were analyzed by counting the number of quadrants each mouse traveled within a constant time period.

EdU administration, labeling, and staining

For cumulative EdU (5-ethynyl-2'-deoxyuridine, Invitrogen) labeling [44], mice received a daily bolus of EdU by i.p. injection (100 $\mu \mathrm{l}$ of $\left.1 \mathrm{mg} \mathrm{ml}^{-1} \mathrm{EdU}\right)$ during the first 6 or 13 days immediately following the last MPTP bolus or from days 9 to 13 after MPTP treatment. Mice were killed at days 6 or 14 after MPTP treatment. Development of EdU staining was performed always after incubation of sections or flatmounts with primary antibodies against cell markers and secondary antibodies. After incubation with the secondary antibody, brain and retinal sections or retinal flatmounts were fixed with $4 \%$ paraformaldehyde in PBS solution for $15 \mathrm{~min}$, washed once with $3 \% \mathrm{BSA}$ in $100 \mathrm{mM}$ PBS, followed by permeabilization with $100 \mathrm{mM}$ PBS, pH 7.4/0.5 \% Triton X-100 for 20 min. Finally, specimens were incubated with the EdU detection cocktail for $30 \mathrm{~min}$ as per the manufacturer's instructions (ClickiT $^{\circledR}$ EdU Alexa 488 Imaging Kit, Invitrogen, Carlsbad, CA, USA).

\section{Immunohistochemistry reagents}

List of primary and secondary antibodies are described in Supplementary Materials and Methods.

Tissue collection for morphological and morphometric analyses

Collection, processing, and immunostaining of brain and retina specimens for morphometric analyses are described in detail in Supplementary Materials and Methods.

\section{Immunohistochemistry}

Free-floating $50-\mu \mathrm{m}$ coronal sections of selected brain regions, $12-\mu \mathrm{m}$ frozen retinal sections mounted on slides or flat-mount retinas were incubated in blocking buffer (PBS, $\mathrm{pH} 7.4$, containing $0.1 \%$ Triton X-100, $10 \%$ normal goat serum) at room temperature for $1 \mathrm{~h}$ followed by an incubation with primary antibody in incubation buffer (PBS, $\mathrm{pH} 7.4$, containing $0.1 \%$ Triton X-100, $5 \%$ normal goat serum) overnight at room temperature (brain) or $4{ }^{\circ} \mathrm{C}$ (retina). After three times of washing with washing buffer (PBS with $0.1 \%$ Triton $\mathrm{X}-100$ ) for $10 \mathrm{~min}$, specimens were incubated in incubation buffer for $2 \mathrm{~h}$ with one or more Alexa-conjugated secondary antibody (1:1,000; Invitrogen, Carlsbad). Specimens were washed three times with washing buffer and whenever applicable mounted on glass slides for visualization and image acquisition with a Nikon 90i C1 Plus confocal microscope.

\section{TUNEL assays}

Detection of apoptosis was carried out in situ in brain and retinal sections with the DeadEnd Fluorimetric TUNEL System (Promega) exactly as described elsewhere [31].

\section{Metabolomic profiling}

Unbiased metabolomic profiling of whole brains of wildtype and Ranbp2 $2^{+/-}$mice 6 days after MPTP treatment was performed by Metabolon, Inc. (Durham, NC). Brains were immediately stored at $-80{ }^{\circ} \mathrm{C}$ after dissection and upon discarding the olfactory bulb and cerebellum. The brains were then provided to Metabolon, Inc. Additional metabolomic methodologies employed by Metabolon are described in Supplementary Materials and Methods.

\section{Biochemical assays}

Immediately after the mice were killed, tissues were collected, snap frozen in liquid nitrogen, and stored at $-80{ }^{\circ} \mathrm{C}$ in a freezer. Liver, midbrain, and striatum tissue extracts in $250 \mu \mathrm{l}$ of NP-40 were prepared using Precellys ${ }^{\circledR} 24$ dual tissue homogenizer (Bertin Technologies, MontignyleBretonneux), at 6,000 rpm for $23 \mathrm{~s}$. Total cholesterol, free cholesterol, and esterified cholesterol were measured as previously described [31]. Levels of Coenzyme A were determined by the Coenzyme A Assay Kit (Biovision, Mountain View, CA, USA) as directed by the manufacturer. Results were normalized against protein amounts in NP40 tissue extracts used for each assay. Two-sample $t$ test statistical analyses with the assumption of unequal variance were performed; $p \leq 0.05$ was defined as significant.

\section{Results}

Haploinsufficiency of Ranbp2 causes increased akinesia and slow recovery upon MPTP treatment

To assess the effects of MPTP on dopaminergic neurons and glial cells of the brain and retina of wild-type and haploinsufficient Ranbp2 mice, 24-week-old inbred mice were subjected to a protocol of acute exposure of MPTP followed by time-course examination of their motility in an open-field test, state of $\mathrm{TH}^{+}$-neurons and glial cells of the brain and retina, and changes in brain metabolites (Fig. 1). As shown in Fig. 2a, there were no significant differences in basal locomotors activity between wild-type and Ran$b p 2^{+/-}$mice the day before MPTP treatment began, but 


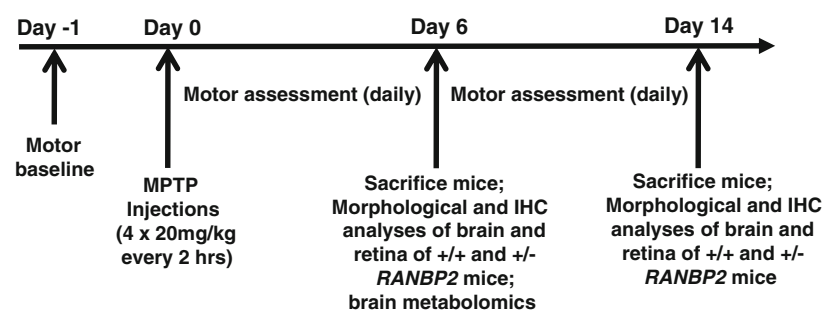

Fig. 1 MPTP treatment and experimental time line. The baseline motor activities of wild-type and Ranbp $2^{+/-}$mice were assessed the day prior to the MPTP treatment $($ Day -1$)$. Wild-type and Ranbp2 $2^{+/-}$ mice on an inbred 129P2/OlaHsd background underwent four bolus of MPTP i.p. injections spaced $2 \mathrm{~h}$ apart. The motor activities of the mice were assessed daily; brain and retinal tissues were collected for analyses at days 6 and 14 after MPTP treatment. Metabolic profiling was performed with brains of wild-type and Ranbp $2^{+/-}$mice at day 6 after MPTP treatment

there was a stronger decline followed by a slower recovery phase in Ranbp $2^{+/-}$than wild-type mice after MPTP treatment. Further, not all Ranbp $2^{+-}$compared to wildtype mice recover their motility at the end of the 14-day experimental procedure (Fig. 2b).

MPTP promotes transient nuclear atypia in brain $\mathrm{TH}^{+}$-neurons of Ranbp $2^{+/-}$mice

We then performed morphometric analyses of coronal sections between wild-type and Ranbp $2^{+/-}$mice of cell bodies of $\mathrm{TH}^{+}$-neurons at the end of the 14-day experimental procedure and encompassing the following regions of the mesencephalic dopaminergic network: such as substantia nigra pars compacta ( $\mathrm{SNc})$, ventral tegmental area (VTA), locus coeruleus (LC), and periaqueductal gray area (PAGA) (Fig. 3a, b). We found no significant changes in the number of $\mathrm{TH}^{+}$-neurons between non-treated and treated mice of either genotype. We also examined the striatum, which contains axons and synaptic terminals of the $\mathrm{TH}^{+}$-neurons, for density changes of $\mathrm{TH}^{+}$-axons and synaptic terminals. No remarkable differences in $\mathrm{TH}^{+}$neurons were detected between treated mice of either genotype at 6 or 14 days after MPTP treatment (Supplemental Fig. 1). There was no evidence of apoptosis in all areas of the mesencephalic dopaminergic network by TUNEL assay (data not shown). Likewise, there was no upregulation of glial fibrillary acidic protein (GFAP) throughout the brain sections examined, a process commonly elicited by neuronal injuries of multiple etiologies (data not shown) [45, 46]. The only distinct morphological difference was the development of nuclear atypia in $\mathrm{TH}^{+}$neurons at 6 days after MPTP treatment that was significantly more pronounced in Ranbp $2^{+/-}$than wild-type mice (Fig. 4a, b). The nuclear compartment became hypotrophic as reflected by the prominent and asymmetric clumping of DAPI-stained chromatin of $\mathrm{TH}^{+}$-neurons of Ranbp2 $2^{+/-}$ mice towards an edge of the nuclear compartment (Fig. 4a). These abnormalities disappear, however, by day 14 post-MPTP-treatment, since no differences in the nuclear distribution of DAPI-stained chromatin could be observed with mice of either genotype (Fig. 4a).

MPTP promotes distinct effects between $\mathrm{TH}^{+}$-neurons and $\mathrm{GFAP}^{+}$-glia in retinae of wild-type and Ranbp2 $2^{+/-}$ mice

We also examined the effect of MPTP on $\mathrm{TH}^{+}$-amacrine neurons of the retina, since apparently conflicting reports exist on the reversible decrease of $\mathrm{TH}^{+}$-amacrine
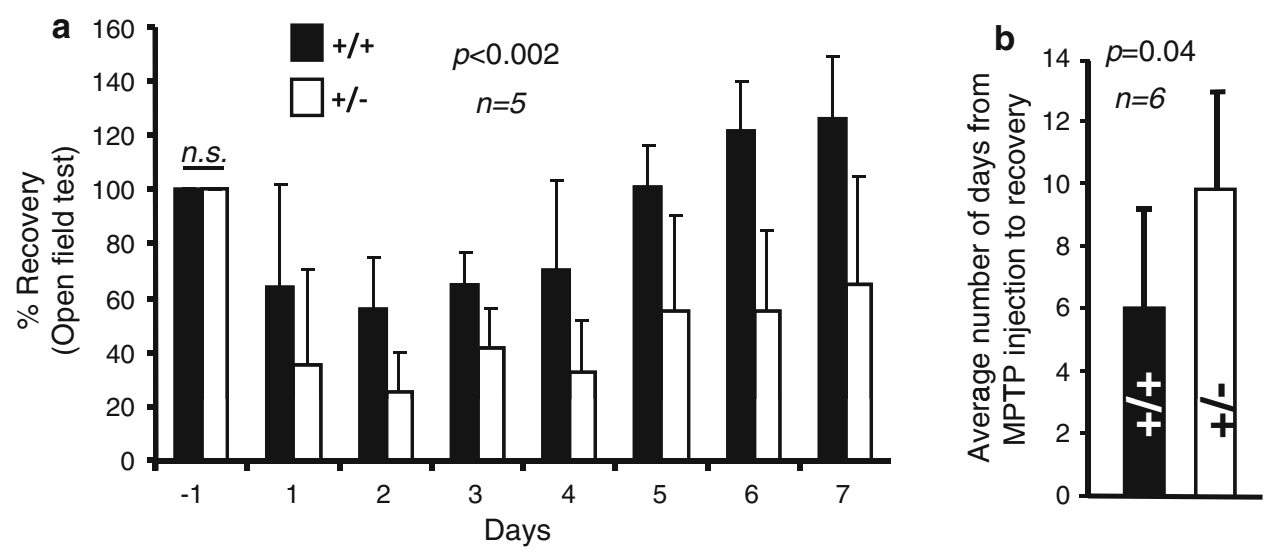

Fig. 2 Motor activities of wild-type and Ranbp $2^{+/-}$mice before and after MPTP treatment. a Motor activities between wild-type and Ranbp $2^{+/-}$mice during the first 7 days after MPTP treatment. Wildtype and Ranbp $2^{+/-}$mice exhibit no significant differences in basal motor activities a day prior to the initiation of MPTP treatment (day -1 ). The decline in motility reached its peak at the second day posttreatment and it plateaued for about 2 days before mice of both genotypes began to regain steadily their motilities. The greatest difference in motility between genotypes was observed at day 6 after MPTP treatment. $\mathbf{b}$ The recovery of the motility of wild-type mice is significantly faster than Ranbp $2^{+/-}$mice. Data shown represent the mean $\pm \mathrm{SD} ; p<0.002, n=5(\mathbf{a}) ; p=0.04, n=6$ (b). Black and white bars represent wild-type and Ranbp $2^{+-}$mice, respectively. n.s. not significant $(p>0.05)$; +/+ wild-type, $+/-$ Ranbp $2^{+/-}$ 

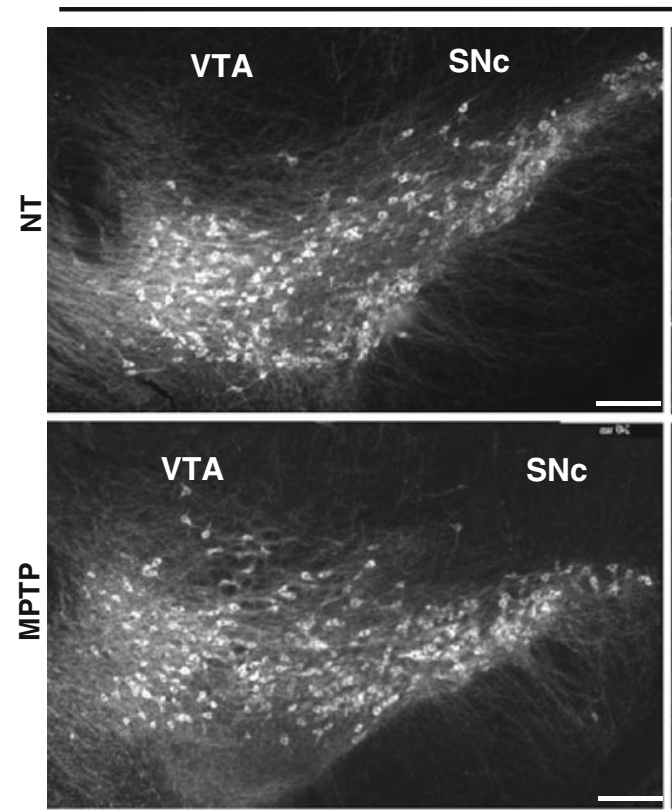
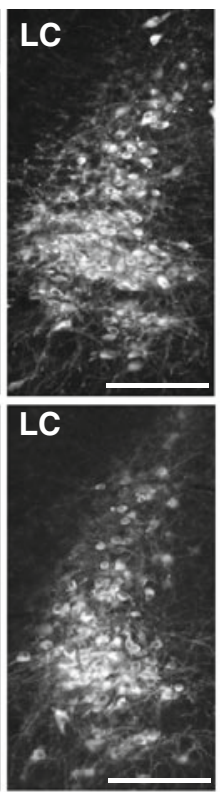

$+/-$
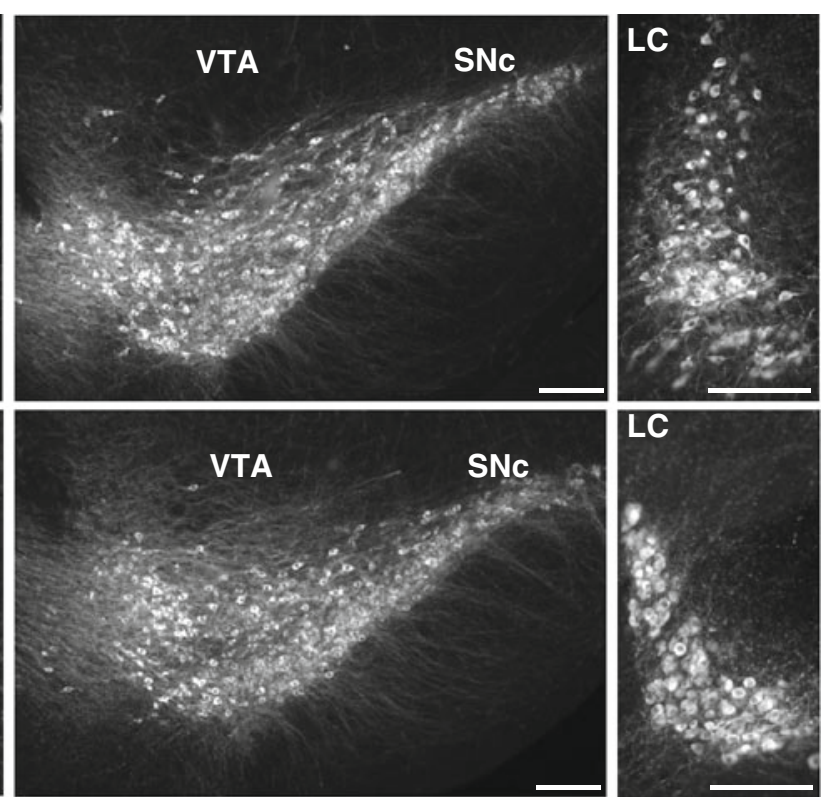

b

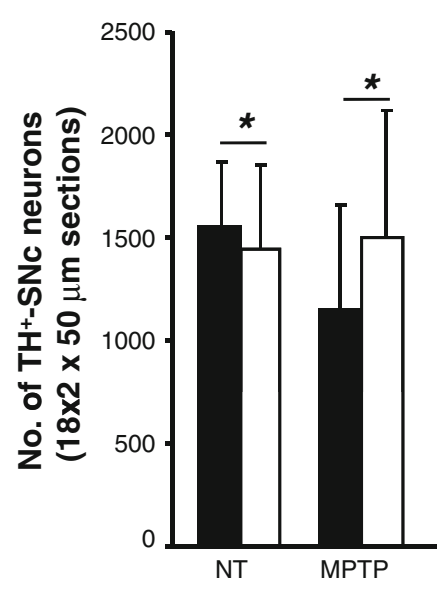

$\square+/+\square+/-\quad *$

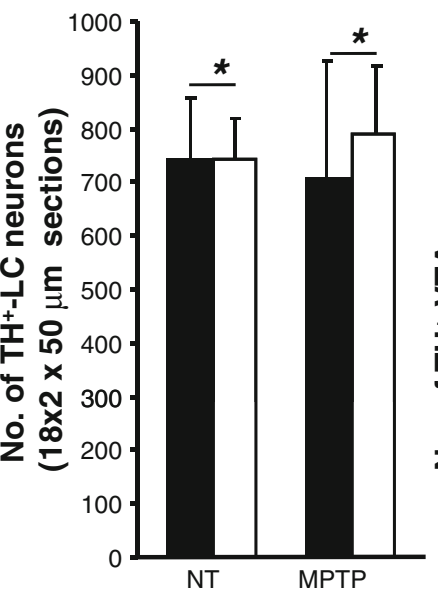

${ }^{\star} p<0.05$
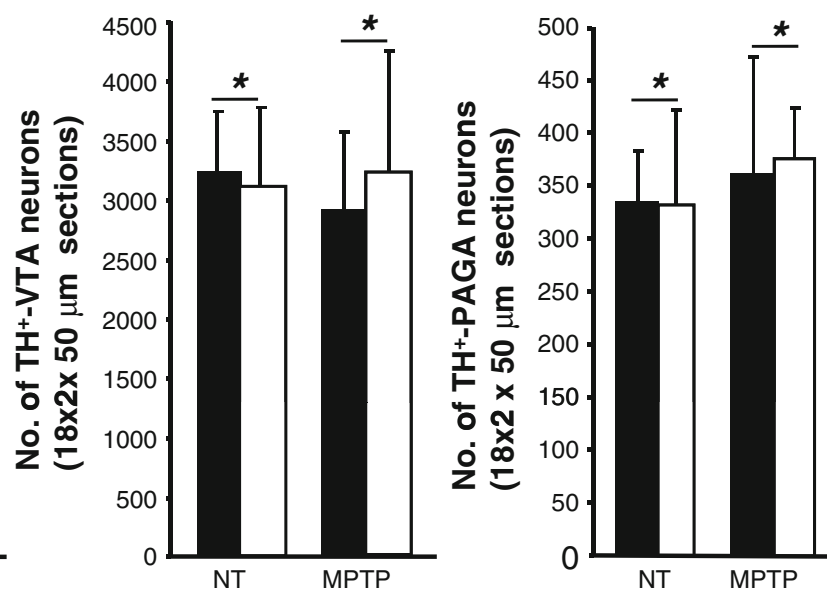

Fig. 3 MPTP does not cause the loss of dopaminergic neurons in various regions of the brain in wild-type and Ranbp2 $2^{+/-}$mice. a Confocal images of $\mathrm{TH}^{+}$-dopaminergic neurons of the substantia nigra pars compacta $(S N c)$, ventral tegmental area $(V T A)$, and locus coeruleus $(L C)$. b Morphometric analyses show no differences in the number of cell bodies of dopaminergic neurons of the SNc, VTA, LC, and periaqueductal gray area (PAGA) between non-treated and

dopaminergic neurons upon MPTP treatment. No significant differences in the number of $\mathrm{TH}^{+}$-amacrine neurons exist between untreated wild-type and Ranbp $2^{+/-}$mice (Fig. 5a). After 6 days of MPTP treatment, however, there were less $\mathrm{TH}^{+}$-amacrine neurons in both genotypes, but such a decrease was greater in Ranbp $2^{+l-}$ than wild-type mice (Fig. 5a). Such a decrease was not caused by the cell death of $\mathrm{TH}^{+}$-amacrine neurons, because we could not detect any TUNEL-positive cells in the inner nuclear or any other
MPTP-treated wild-type and Ranbp $2^{+/-}$mice. Data shown represent the mean \pm S.D, ${ }^{*} p>0.05, n=5$; MPTP-treated mice; $n=3$, nontreated mice. MPTP-treated mice were analyzed 6 days after MPTP treatment. Cell body tallying reflects 18 coronal topographically equivalent sections of $50 \mu \mathrm{m}$ from various regions of each brain hemisphere of wild-type and Ranbp $2^{+/}$mice. +/+ wild-type, $+/-$ Ranbp $^{+/-}$, NT non-treated; scale bars $150 \mu \mathrm{m}$

retinal nuclear layers (data not shown). Notably, the number of $\mathrm{TH}^{+}$-amacrine neurons of $\operatorname{Ranbp}^{+/-}$recovered to levels comparable to those of non-treated mice by day 14 postMPTP treatment, while in wild-type mice they exceeded by $\sim 20 \%$ those observed in non-treated mice (Fig. 5a). In association with this compensatory response, there was an increase of the thickness and intensity of synaptic plexus of $\mathrm{TH}^{+}$-amacrine neurons and the presence of weak immunoreactive $\mathrm{TH}^{+}$-neurons surrounding typically a strongly 

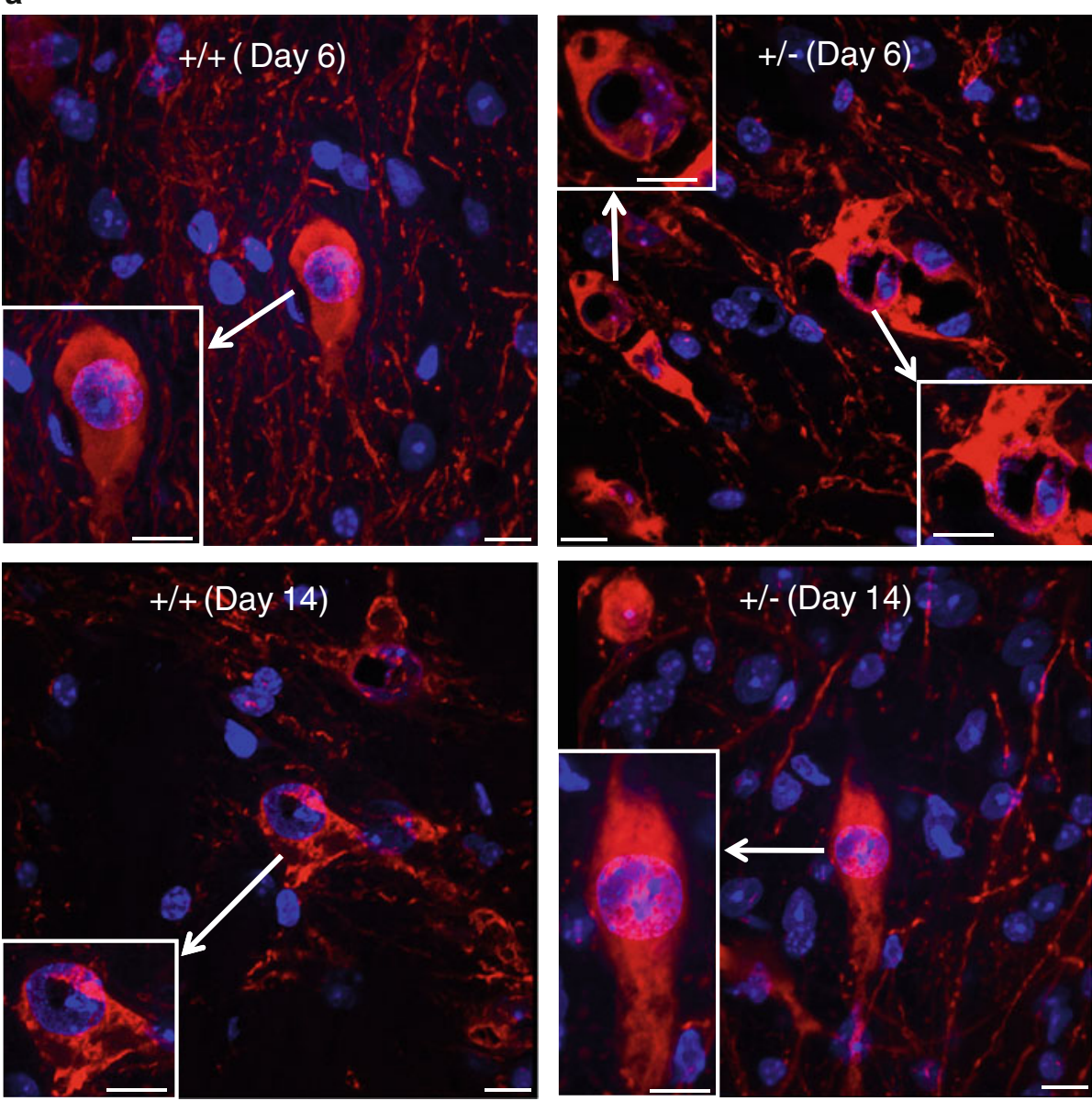

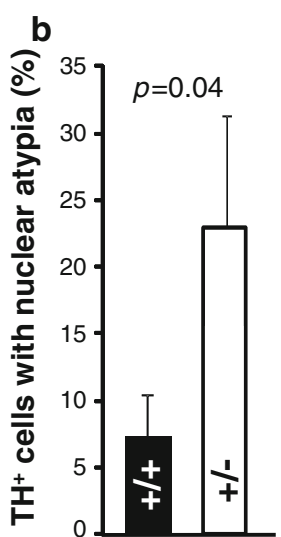

Fig. 4 Ranbp2 haploinsufficiency promotes transient nuclear atypia of $\mathrm{TH}^{+}$-dopaminergic neurons upon MPTP treatment. a Confocal images of $\mathrm{SNc} \mathrm{TH}^{+}$-dopaminergic neurons (red) of wild-type and Ranbp $2^{+/-}$mice counterstained with DAPI at 6 and 14 days after MPTP treatment. Note the asymmetric distribution of clumped chromatin and large nuclear areas voided of DAPI staining (nuclear vacuolization) in $R a n b p 2^{+/-}$, but not wild-type mice, at 6-day post-
MPTP treatment. These phenotypic differences between genotypes disappear at 14-day post-MPTP treatment. Inset pictures large magnifications of cell bodies of $\mathrm{TH}^{+}$-dopaminergic neurons denoted by arrows. Scale bars $10 \mu \mathrm{m}$. b Quantitative analysis of nuclear atypia of $\mathrm{TH}^{+}$-dopaminergic neurons between wild-type and Ran$b p 2^{+/-}$mice at 6-day post-MPTP treatment. Data shown represent the mean $\pm \mathrm{SD}, p=0.04, n=3$. $+/+$ wild-type, $+/-$ Ranbp $^{+/-}$ stained $\mathrm{TH}^{+}$-amacrine neuron in MPTP-treated wild-type, but not treated Ranbp $2^{+/-}$and non-treated mice (Fig. 5b). It is noteworthy that these weak immunoreactive cells were never counted for the quantitative analyses described earlier. Likewise, these effects were accompanied by an increase in the staining of the dopaminergic synaptic plexus for the vesicular monoamine transporter-2 (VMAT2) (Fig. 5c). These changes were also highly selective toward $\mathrm{TH}^{+}$amacrine neurons, because no significant changes were observed in calretinin immunostaining of AII amacrine cells and sublaminar synaptic layers of the inner plexiform layer and Cabp5 immunostaining of rod and cone bipolar neurons in the inner nuclear layer (data not shown).

Stress stimuli of multiple etiologies and causing retinal damage are known to induce the up-regulation of glial fibrillary acidic protein (GFAP) in Müller glial cells [46].
Further, these glial cells are thought to present proliferative capacity and few appear to regenerate into amacrine neurons [46]. Hence, we examined whether MPTP treatment promoted changes in the density of $\mathrm{GFAP}^{+}$-radial glia (Müller cells) of the retina and these cells were the source of the increase in the number $\mathrm{TH}^{+}$-amacrine neurons in MPTP-treated wild-type mice. No remarkable changes of GFAP $^{+}$-Müller cells were seen before and at day 6 after treatment in wild-type and Ranbp $2^{+/-}$mice compared to non-treated mice (Fig. 6a, upper panel; data not shown). However, there was a robust and significant rise of $\mathrm{GFAP}^{+}$-glial cells in retinas of wild-type, but not Ran$b p 2^{+/-}$mice, at day 14 after MPTP-treatment (Fig. 6a) that was most prominent and significant toward the marginal regions of the retinas (Fig. 6a, lower panel; b), even though Müller cells immunostained for its canonical glial marker, 


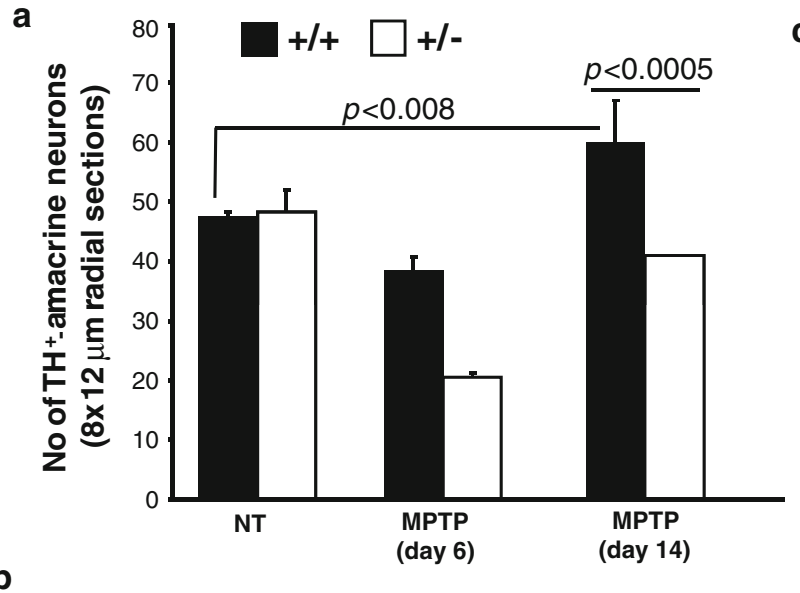

C
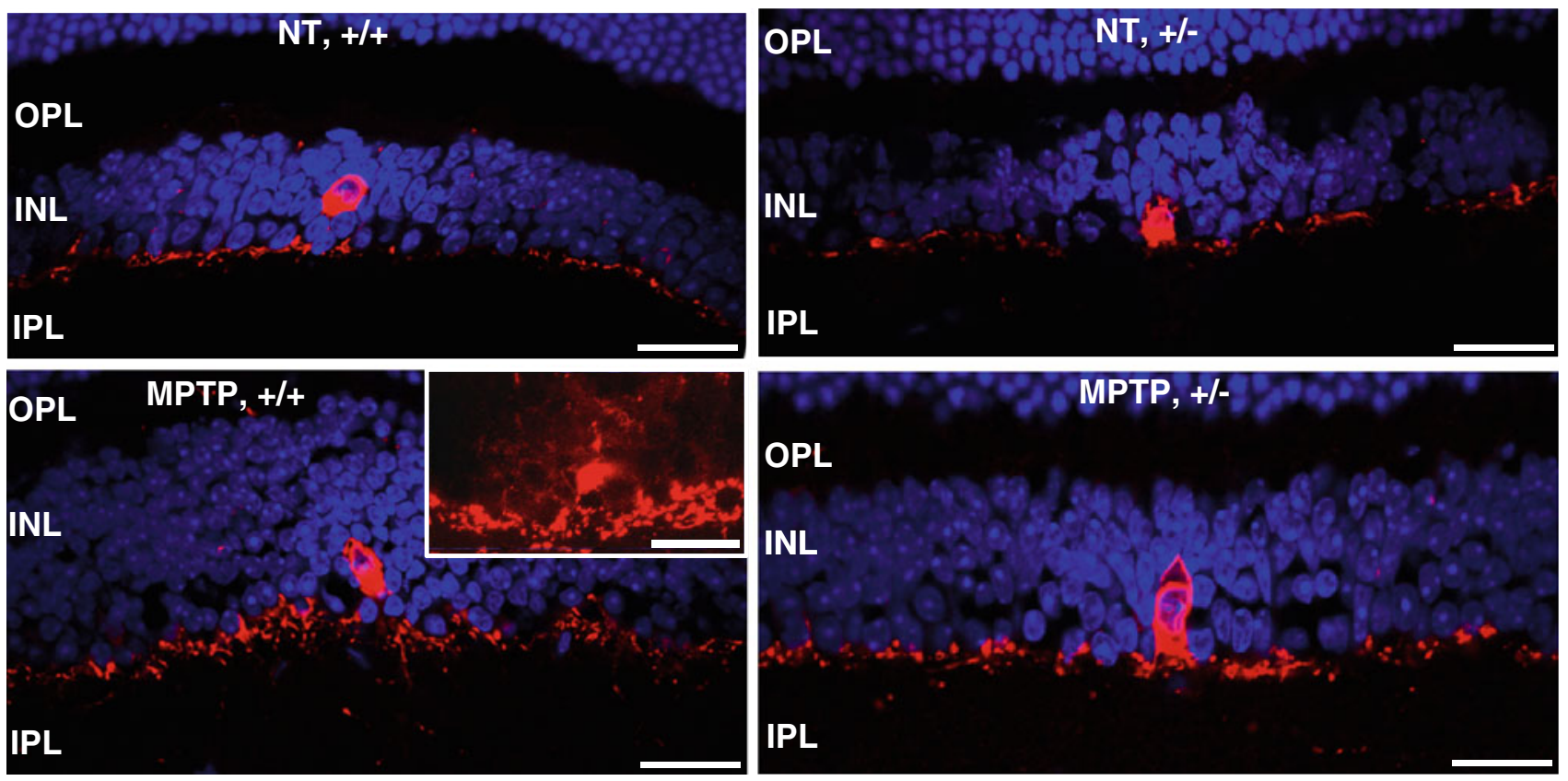

Fig. 5 MPTP elicits a stronger decrease and a slower recovery of the number of retinal $\mathrm{TH}^{+}$-neurons in Ranbp $2^{+/-}$than wild-type mice. a Comparison of the number of $\mathrm{TH}^{+}$-neurons in the retina between Ranbp $2^{+/-}$and wild-type mice before and after MPTP treatment (6 and 14 days post-treatment). Note the stronger recovery of retinal $\mathrm{TH}^{+}$-neurons in wild-type mice 14 days after MPTP treatment surpasses the number of $\mathrm{TH}^{+}$-neurons observed in non-treated wildtype or Ranbp $2^{+/-}$mice. Data shown represent the mean $\pm \mathrm{SD}$; $n=6$, MPTP-treated mice; $n=3$, non-treated mice. b Confocal images of retinal $\mathrm{TH}^{+}$-neurons (red) in non-treated (NT) and 14-day

glutamine synthetase, were distributed evenly throughout the retina regardless of the genotype (Fig. 6c). By contrast, the rise of $\mathrm{GFAP}^{+}$-Müller cells in treated Ranbp $^{+/-}$mice is very tenuous, with only a few GFAP $^{+}$-Müller cells observed at the very marginal and optic nerve head regions of the retina (Fig. 6a, b). Hence, RanBP2 insufficiency suppresses gliosis upon MPTP challenge and this effect outlasts the neurotoxic insult without affecting the general distribution and viability of Müller glial cells.

post-MPTP treated wild-type and $R a n b p 2^{+/-}$mice. Note the increase of the thickness of the $\mathrm{TH}^{+}$-synaptic plexus and the presence of weakly stained $\mathrm{TH}^{+}$-cell bodies surrounding a strongly stained $\mathrm{TH}^{+}$amacrine cell body (inset picture) in wild-type mice 14 days after MPTP challenge. These weakly stained $\mathrm{TH}^{+}$-cell bodies were never observed in retinas of Ranbp2 $2^{+/-}$mice. c The increase of the thickness of the $\mathrm{TH}^{+}$-synaptic plexus was accompanied also by a stronger increase of VMAT2 staining (green) in wild-type than Ranbp $2^{+/-}$mice. $+/+$wild-type, $+/-$Ranbp $^{+/-}$; scale bars $25 \mu \mathrm{m}$

Haploinsufficiency of Ranbp2 suppresses the proliferation of $\mathrm{EdU}^{+}$-cells in the retina that do not regenerate into $\mathrm{TH}^{+}$-amacrine neurons upon MPTP treatment

The suppression of the recovery phase of $\mathrm{TH}^{+}$-amacrine neurons in Ranbp2 $2^{+/-}$mice at days 6 and 14 after MPTP treatment (Fig. 5a) hints that insufficiency of RanBP2 suppresses the proliferation of progenitor retinal cells 

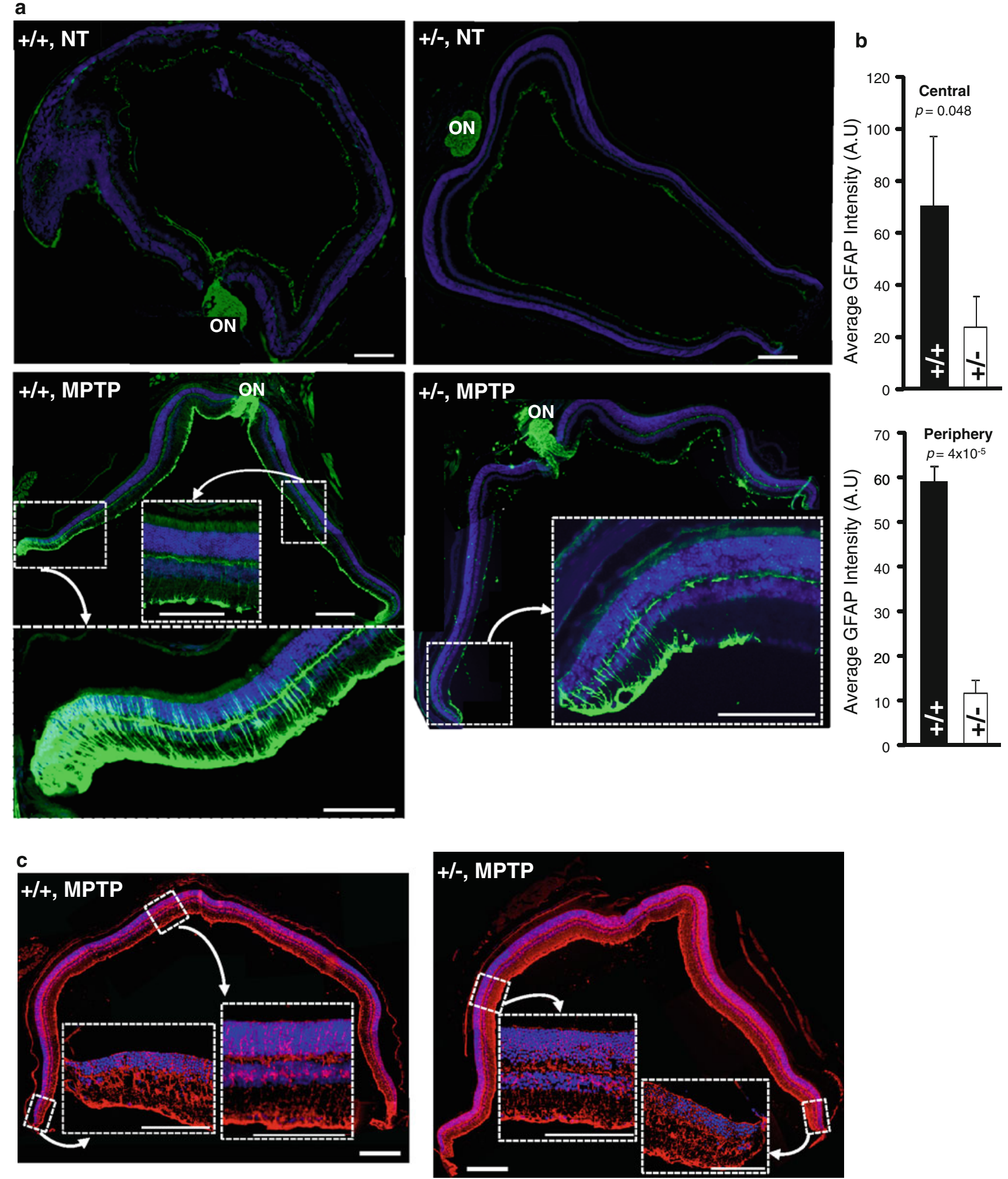

capable of regenerating into $\mathrm{TH}^{+}$-amacrine neurons or the differentiation of existing cells by the up-regulation of dopaminergic markers. Hence, we analyzed retinas of mice that underwent MPTP treatment and three different regimens of injections with the thymidine analog, 5-ethynyl-2-deoxyuridine (EdU), which incorporates into the DNA of proliferative cells [44]. The EdU modality treatments comprised daily EdU injections during the first 
४Fig. 6 Ranbp2 haploinsufficiency suppresses MPTP-elicited gliosis in the retina. a Non-treated mice exhibit extremely weak GFAP staining of Müller cells across the retina. In contrast, there is a prominent centrifugal increase of the number of GFAP $^{+}$-Müller cells in retinas of MPTP-treated wild-type mice that are strongly decreased in Ranbp $^{+/-}$mice 14 days after MPTP treatment. Strong GFAP immunoreactivity is also observed in the optic nerve head (ON). Inset pictures denoted by the arrows are high magnifications of boxed peripheral or central regions of the retina. $\mathbf{b}$ Quantitative analyses of immunofluorescence intensity of $\mathrm{GFAP}^{+}$-Müller cells in central and peripheral regions of retinas of wild-type and $R a n b p 2^{+/-}$mice 14 days after MPTP treatment (as shown in a). Data shown represent the mean $\pm \mathrm{SD} ; n=3$. $\mathbf{c}$ The significant differences in the density of $\mathrm{GFAP}^{+}$-Müller cells observed between wild-type mice and Ran$b p 2^{+/-}$mice in a are not accompanied by differences in staining of the canonical glial (Müller) marker, glutamine synthetase, which, in contrast to GFAP, stains uniformly the glial cells across the retina. Inset pictures denoted by the arrows are high magnifications of peripheral or central regions of the retina. +/+ wild-type, +/Ranbp $2^{+/-}$, A.U. arbitrary units, $O N$ optic nerve head; scale bars $200 \mu \mathrm{m}$

5 days, between days 9 and 13, or throughout the 13 days of the experimental procedure. Retinas were then analyzed the day after the last EdU injection. Quantitative analyses of confocal images scanned across a 50- $\mu \mathrm{m}$ depth of the mid-plane of flatmount retinas of 5-day EdU-treated mice showed that Ranbp $2^{+/-}$had a significantly less number of $\mathrm{EdU}^{+}$-cells than wild-type mice (Fig. 7a). Such a genotype-dependent decrease of proliferating cells was also qualitatively observed with the other two regimens of EdUtreatment. Regardless of the EdU-regimen modality and genotype, we never detected co-labeling of single $\mathrm{TH}^{+}$amacrine neurons with EdU (Fig. 7b). These data support that the changes in the number of $\mathrm{TH}^{+}$-amacrine neurons result from the genotype-dependent modulation of expression of $\mathrm{TH}$, and possibly of other dopaminergic markers, such as VMAT2, rather than from the proliferation of progenitor cells.

We then examined the identity of the EdU ${ }^{+}$- cells, whose proliferation was suppressed in Ranbp $2^{+/-}$mice upon MPTP treatment, with antibodies against antigens known to be either expressed in retinal progenitor cells or markers upregulated in proliferating cells upon retinal injury. In particular, Sox 2 is known to be required for differentiation of progenitor cells to amacrine and other retinal neurons [47], whereas GFAP, CD45, and CD11b are markers for Müller glia and astrocytes, vascular (leukocytes), and resting and activated microglia and macrophages, respectively [48-50]. $\mathrm{GFAP}^{+}-\mathrm{CD} 45^{+}$, and $\mathrm{CD} 11 \mathrm{~b}^{+}$-cells are known to proliferate upon retinal damage to various stress stimuli [50-52]. As shown in Fig. 7c-f, most cellular markers tested were expressed in $\mathrm{EdU}^{-}$cells, albeit with some differences. Among the $\mathrm{GFAP}^{+}$cells, only very few were $\mathrm{EdU}^{+}$, thus supporting $\mathrm{GFAP}^{+}$-cells represent a small fraction of
$\mathrm{EdU}^{+}$-proliferating cells (Fig. 7c). In the retina, all CD45 were $\mathrm{EdU}^{-}$(Fig. 7d) and the few $\mathrm{CD} 45^{+} \mathrm{EdU}^{+}$identified in several sections were exclusively localized in the choroid plexus (Fig. 7e). All CD11b ${ }^{+}$cells identified were $\mathrm{EdU}^{--}$ cells and they appeared to be macrophages that were also exclusively localized in the choroid plexus (Supplementary Fig. 2). Finally, we did not identify $\mathrm{EdU}^{+}-\mathrm{Sox} 2$ cells (Fig. 7f). Hence, the majority of the EdU ${ }^{+}$-cells in the retina represents cells of novel origin or identity.

Ranbp2-dependent metabolic imbalances in the brain upon exposure to acute MPTP treatment

In light of the temporal differences in behavioral and cellular phenotypes observed between inbred wild-type and Ranbp $2^{+/-}$mice upon MPTP treatment, we took an unbiased metabolomic approach to examine differences in metabolite profiles that contribute to genotype-dependent manifestations outlasting the effects of MPTP. We employed brain tissue without the olfactory bulb and cerebellum, because of the amount of tissue needed to perform metabolomic analysis, a requirement the retinal tissue does not meet, and no differences in the gross cellular composition of the brain were observed between mice of either genotype, an outcome that would otherwise skew the metabolic profile. We performed metabolomics on mice 6 days after MPTP treatment, because this was the time point when there was the greatest difference in locomotor activity between wild-type and Ranbp $2^{+/-}$mice (Fig. 2a). This metabolomic approach led to the identification of 17 metabolites, which were significantly altered between treated wild-type and Ranbp $2^{+/-}$mice with an identical inbred 129P2/OlaHsd genetic background $(p<0.05)$ (Fig. 8a), and of another 13 metabolites, which narrowly missed the $p<0.05$ cutoff (e.g., hippurate, myo-inositol, homocarnosine, phosphopantetheine with $p=0.0535$, $0.0538,0.0618$, and 0.066 , respectively) or with trends approaching significance $(0.05<p<0.10)$ (Fig. 8b). The inclusion of trend differences further aided the interpretation of changes in metabolites and metabolic pathways deemed to undergo significant changes.

The variations in metabolites observed between genotypes upon MPTP treatment could be divided into five major groups based on the role(s) and mapping of a set of metabolites into metabolic pathways according to the Kyoto Encyclopedia of Genes and Genomes (KEGG) (Fig. 9). The first group comprises three metabolite subsets, whose levels are thought to affect interdependent metabolic pathways. The first subgroup is characterized by a decrease of lipid metabolites or precursors thereof (Figs. 8, 9a). In particular, we found a significant decrease of two essential medium-chain free fatty acids, pelargonate 
a

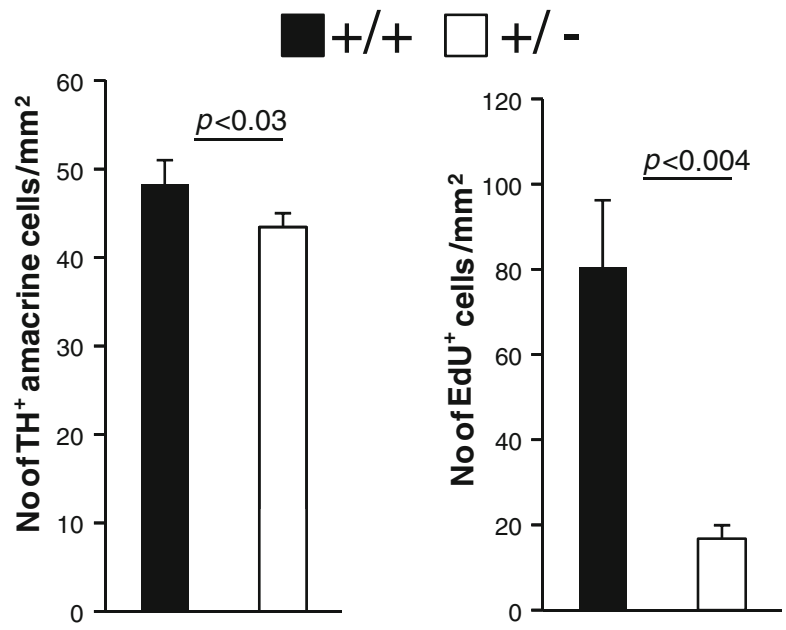

b
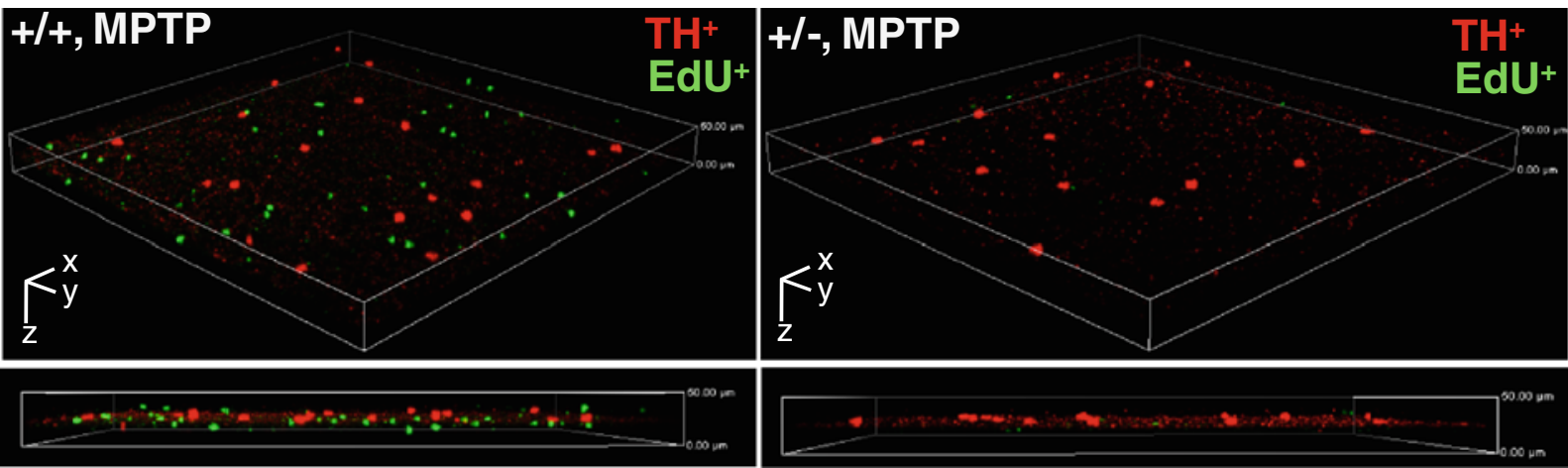

c

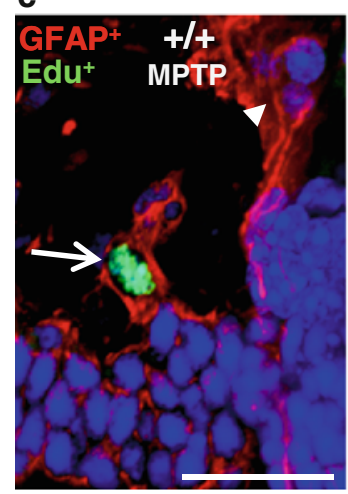

d

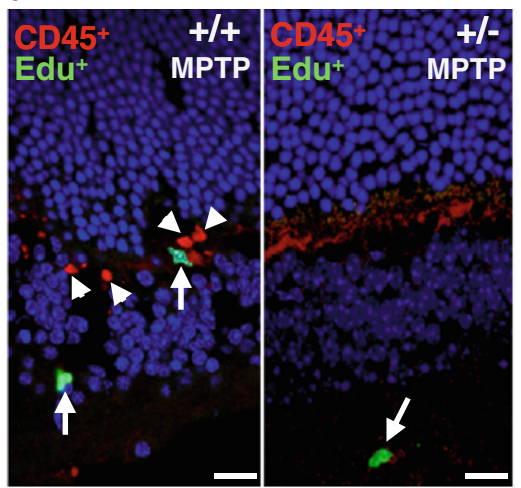

e

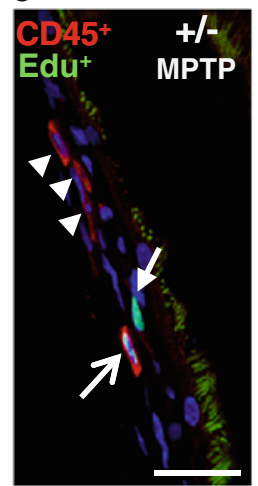

f

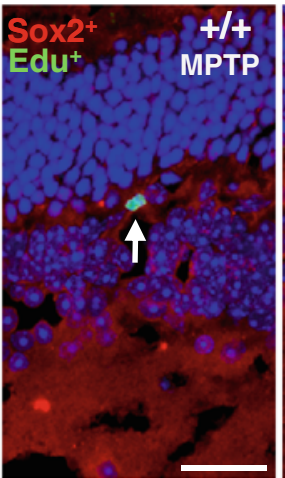

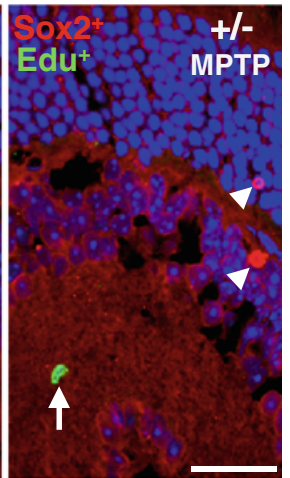

Fig. 7 Retinal cellular proliferation elicited by MPTP is suppressed by insufficiency of RanBP2 and it lacks canonical dopaminergic, inflammatory, and vascular cellular markers. a The decrease of the number of $\mathrm{TH}^{+}$-amacrine neurons is accompanied by a strong decrease of $\mathrm{EdU}^{+}$-proliferating cells in Ranbp $2^{+/-}$compared to wildtype mice 6 days after MPTP treatment. Data shown was collected from images of flat-mount retinas and represent the mean $\pm \mathrm{SD}$; $n=4$, wild-type; $n=5$, Ranbp $2^{+/-}$. b $3-\mathrm{D}$ reconstruction of confocal $x-y-z$ image stacks across a $50-\mu \mathrm{m}$ depth of the inner nuclear and plexiform layers of the retina and depicting the nonoverlapping spatial arrangement of cell bodies of $\mathrm{TH}^{+}$-amacrine neurons (red) and EdU ${ }^{+}$-cells (green) 6 days after MPTP treatment in wild-type and Ranbp $2^{+-}$mice. Ranbp $2^{+/-}$mice present far fewer $\mathrm{EdU}^{+}$-cells than do wild-type mice. The images below the 3-D images are 2-D cross sections of collapsed 3-D images. Scale bars: $x 635.5 \mu \mathrm{m}, y 635.5 \mu \mathrm{m}, z 50 \mu \mathrm{m}$ with cell bodies of $\mathrm{TH}^{+}$-amacrine neurons occupying the mid-plane of the $z$-stack. c Only few $\mathrm{GFAP}^{+}$cells $(r e d)$ in the retina were co-labeled by EdU (green) in wild-type mice; $\mathrm{GFAP}^{+}$-cells are shown with (arrow) and without (arrowhead) EdU labeling. d No CD45 ${ }^{+}$-cells (red, arrowhead) in the retina were observed to be labeled by EdU (green, arrow) in mice of either genotype, although in the choroid plexus few $\mathrm{CD} 45^{+}$-cells were colabeled by EdU (arrow) (e). f No Sox $2^{+}$-cells (red, arrowhead) in the retina were observed to be labeled by EdU (green, arrow) in mice of either genotype. Images $\mathbf{c}-\mathbf{f}$ are representative retinal sections of mice provided with a daily EdU bolus for 13 days after MPTP treatment. $+/+$ wild-type, +/-Ranbp $2^{+/-}$ 


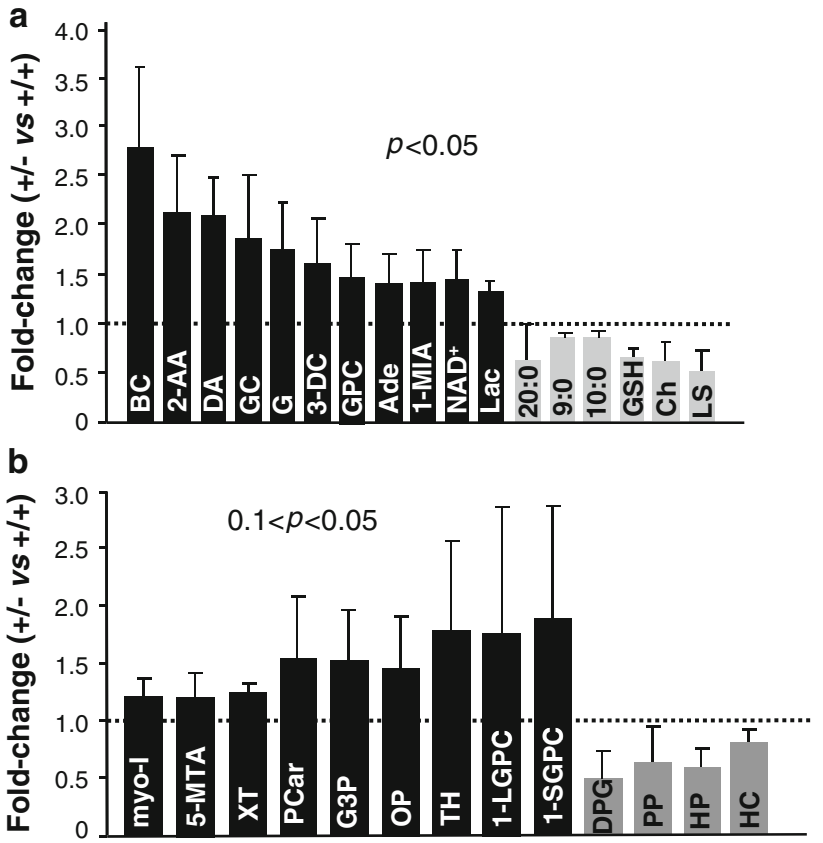

Fig. 8 Metabolomic alterations between $R a n b p 2^{+/-}$and wild-type mice upon MPTP treatment. a Fold-changes in brain metabolites of Ranbp $2^{+/-}$relative to wild-type mice 6 days after the acute MPTP insult. Data represent the mean $\pm \mathrm{SD}$ and metabolites with significant variations (Wilcoxon $p<0.05$ ),$n=5$ for all metabolites but $\mathrm{BC}$, $\mathrm{DA}$, Lac, GSH, and Ch $\left(n=5\right.$, wild-type; $\left.n=4, \operatorname{Ranbp}^{+/-}\right), \mathrm{G}$ $\left(n=4\right.$, wild-type; $\left.n=5, \operatorname{Ranbp} 2^{+/-}\right)$and $\operatorname{NAD}^{+}(n=4)$. b Foldchanges in brain metabolites of $\operatorname{Ranbp} 2^{+/-}$relative to wild-type mice 6 days after MPTP challenge that narrowly missed or approached statistical significance (Wilcoxon $0.1<p<0.05$ ). Data represent the mean $\pm \mathrm{SD}, n=5$. Black and grey bars represent higher and lower levels of metabolites in Ranbp $2^{+/-}$relative to wild-type mice, respectively. GPC glycerophosphorylcholine, 1-MIA 1-methylimidazoleacetate, 3-DC 3-dehydrocarnitine, $G C$ glutaroyl carnitine, 2- $A A$ 2-aminoadipate, 20:0 arachidate, 9:0 pelargonate, 10:0 caprate, $L S$ lathosterol, Ade adenine, $D A$ dehydroascorbate, $B C$ butyrylcarnitine, $G$ glucose, $L$ lactate, $N A D^{+}$nicotinamide adenine nucleotide, $G S H$ glutathione (reduced), Ch cholesterol, 1-LGPC 1-linoleoylglycerophosphocholine, 1-SGPC 1-stearoylglycerophosphocholine, DPG 1,3dipalmitoylglycerol, $P P$ phosphopantetheine, $H P$ hippurate, $H C$ homocarnosine, TH threonate, myo-I myo-inositol, 5-MTA 5-methylthioadenosine, Pcar propionylcarnitine, G3P glycerol 3-phosphate, $X T$ xanthosine, $L a c$ lactate, $O P$ ophthalmate

(9:0) and caprate (10:0) (0.85-fold), and the long-chain free fatty acid, arachidate (20:0) (0.75-fold) in Ranbp $2^{+/-}$mice. Likewise, there is a strong and significant decrease in lathosterol ( 0.53 -fold), a canonical whole-body indicator of cholesterol synthesis [53, 54]. Indeed, a significant decrease of cholesterol levels (0.61-fold) was observed. These deficits were also accompanied by a trend for a decrease of the levels of phosphopantetheine ( 0.63 -fold), a key precursor for the synthesis of the cofactor, coenzyme (CoA), which is critical for the synthesis of free fatty acids and cholesterol [55]. It is of interest to note that the fold-changes in levels of CoA and one of its intermediate precursors, $3^{\prime}$-dephosphocoenzyme $\mathrm{A}$, had the same magnitude of phosphopantetheine (0.63-fold), even though the differences of the mean levels of $3^{\prime}$-dephosphocoenzyme A and CoA between genotypes were not statistically significant.

The second subset comprises a significant rise in Ran$b p 2^{+/-}$mice of the levels of several carnitine conjugates, such as 3-dehydrocarnitine (1.6-fold) and glutaroyl carnitine (1.87-fold), and a trend for an increase in propionylcarnitine (1.55-fold). These surges are also accompanied by an increase of 2-aminoadipate (2.13-fold), an intermediate in lysine metabolism. The rise of the metabolites of this group is likely due to an increase of lysine catabolism, because of increases in the levels of 2-aminoadipate, 3-dehydrocarnitine, and glutaroyl carnitine. Further, odd-chain acylcarnitines, such as propionylcarnitine $(\mathrm{C} 3)$, are produced during amino acid catabolism [56]. Interestingly, we found the levels of several other acylcarnitines, such as butyrylcarnitine, acetylcarnitine, palmitoylcarnitine, stearoylcarnitine, and oleoylcarnitine, to be elevated in Ranbp $2^{+/-}$mice. The changes in these acylcarnitines levels represented some of the greatest fold increases of this study (from 1.55- to over threefold) and there was a significant correlation between their elevated levels in Ranbp $2^{+/-}$mice $\left(r_{\mathrm{s}}>0.9 ; p<0.037\right)$ even though the differences of the mean levels of each between genotypes were not significant. Acylcarnitines transport long-chain and medium-chain fatty acids into the mitochondria for energy generation via $\beta$-oxidation and together with reduced levels of coenzyme A, they likely contribute to the accumulation of acylcarnitines [57].

Finally, the last subgroup is characterized by significant increases of glycerophosphorylcholine (1.48-fold), glucose (1.76-fold), lactate (1.36-fold), nicotinamide adenine dinucleotide $\left(\mathrm{NAD}^{+}\right)$(1.45-fold), and dehydroascorbate (2.1-fold). These changes are accompanied also by increased trends of the levels of glycerol 3-phosphate (1.54-fold), myo-inositol (1.22-fold), and threonate (1.78-fold). Altogether, the accumulation of these metabolites may arise from an impairment of the glycerophosphate shunt and reduced anaplerosis of the Krebs cycle [58]. Glycerophosphorylcholine and myo-inositol are also cellular osmolytes with important roles in maintaining cellular volume in response to hypertonic stress [59].

The rise in lysine catabolism in Ranbp2 $2^{+/-}$mice also correlates directly with changes in a second group of metabolites, 1-methylimidazoleacetate (t-MIAA; 1.43-fold) and homocarnosine/ $\gamma$-aminobutyryl-L-histidine (0.81-fold) (Figs. 8, 9b). The significant increase of the former results from the enhanced catabolism of histidine to histamine and it is a reliable marker of histamine turnover rate [60] and such augmented conversion likely induces a decrease of the levels of the dipeptide homocarnosine [61]. This dipeptide is formed from $\gamma$-aminobutyric acid (GABA) and histidine, and it is found mostly in the brain, where it may act as a 


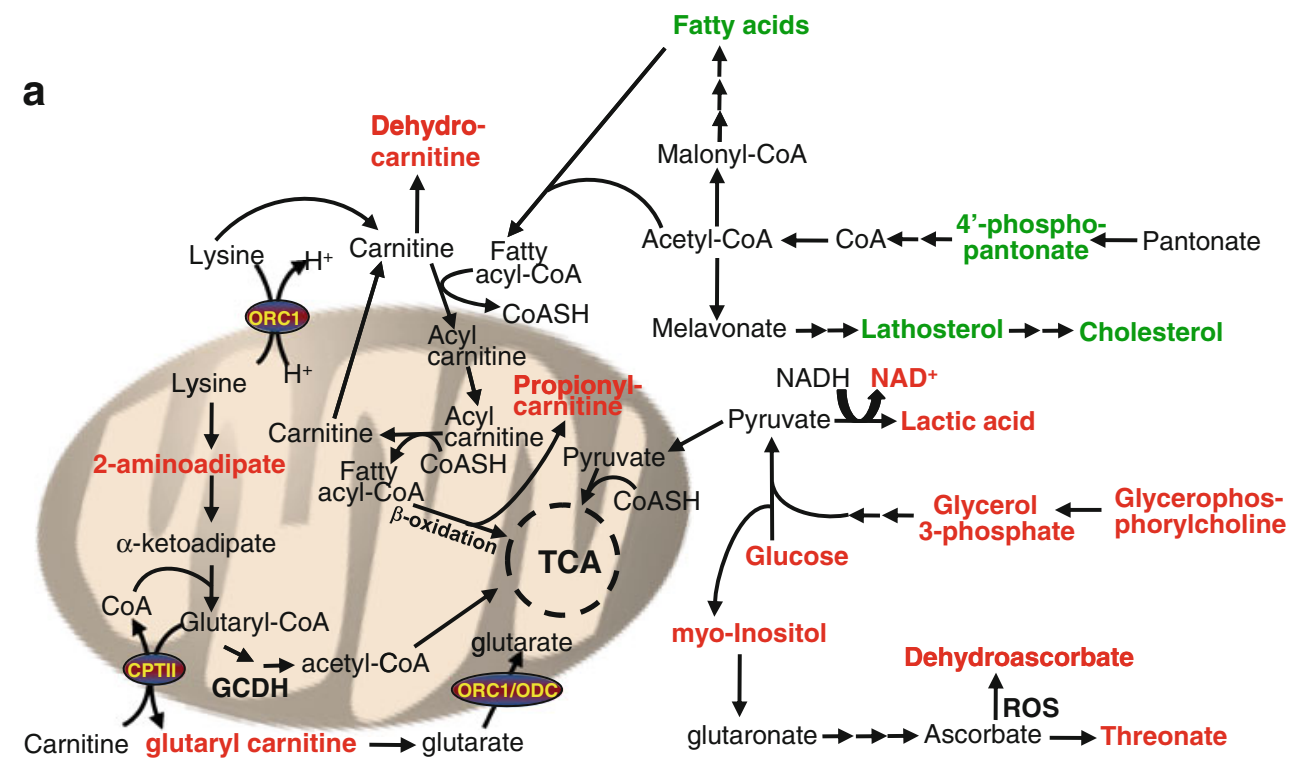

b

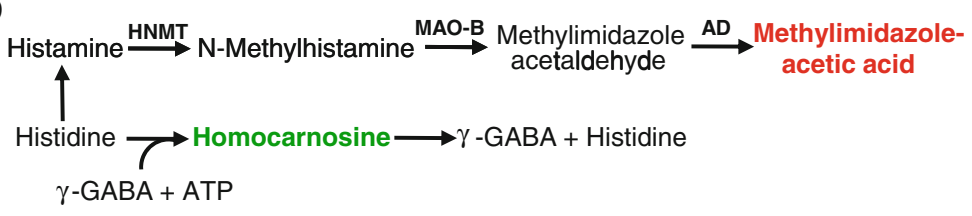

C

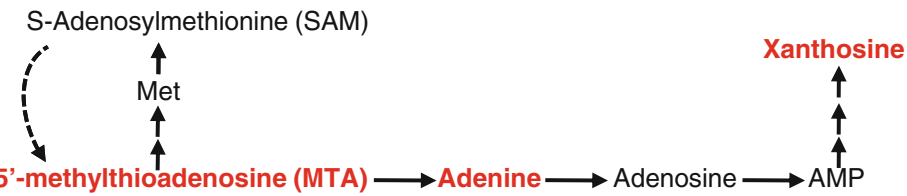

d

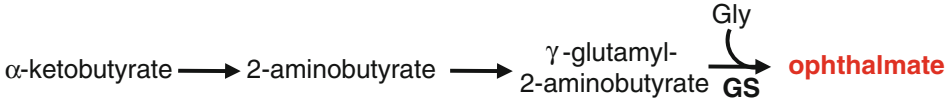

e

S-benzoate-CoA + glycine $\longrightarrow$ Hippurate $+\mathrm{CoA}$

Fig. 9 Model of metabolic deregulation in the brain by RanBP2 insufficiency upon MPTP insult. Alterations of brain metabolites by RanBP2 insufficiency upon acute MPTP exposure were subdivided into five major groups (a-e). Metabolites of group a participate in depicted multistep and interdependent metabolic pathways regulating bioenergetics in the cytosol or mitochondria related to lipid and glucose metabolism and cofactors thereof. These metabolites can be further divided into three subsets: lipid metabolites or precursors and cofactors thereof, acylcarnitine conjugates and metabolites of lysine catabolism, bioenergetic metabolites/substrates, and cofactors thereof (e.g., glycerophosphorylcholine, glucose, lactate, $\mathrm{NAD}^{+}$) that likely

GABA reservoir, the main neurotransmitter inhibitor of the brain. Notably, the immediate precursor of t-MIAA, methylimidazole acetaldehyde, is the metabolite of the oxidative deamination of $\mathrm{N}$-methylhistamine by the monoamine oxidase type B (MAO-B), which also metabolizes dopamine upon its oxidative deamination and converts MPTP to promote reduced anaplerosis of the Krebs cycle. Metabolites of group b reflect changes in histidine catabolic pathways, whereas those of group $\mathbf{c}$ represent variations in the methionine and adenine salvage pathways. Metabolites of groups $\mathbf{d}$ and $\mathbf{e}$ represent changes in conjugation reactions with glycine, reflecting variations of redox pathways (group d) and detoxification reactions (group e). See text for further details. Metabolites in red and green are, respectively, upregulated and down-regulated; single and multiple arrows represent single and multi-step pathways. $M A O-B$ monoamine oxidase, type $B$ $O R C 1$ ornithine carrier, $C P T I I$ carnitine palmitoyltransferase II, $O D C$ oxodicarboxylate carrier, $O G C$ oxoglutarate carrier

$\mathrm{MPP}^{+}$. MAO-B is also a therapeutic target for Parkinson's disease.

The third group reflects a rise of metabolites of the methionine and adenine salvage pathways in Ranbp $2^{+/-}$ mice (Figs. 8, 9c). There was a significant 1.4-fold increase of adenine that was accompanied by strong trends of a rise 
of the levels of 5-methylthioadenosine (1.32-fold) and xanthosine (1.32-fold). Finally, the fourth and fifth groups are represented by the metabolites, reduced glutathione (GSH) (0.65-fold) and ophthalmate (1.47-fold), and hippurate (0.59-fold), respectively (Figs. $8,9 \mathrm{~d}$, e). Ophthalmate and hippurate metabolites arise from the conjugation reactions with glycine. Hippurate is a common metabolite of detoxification reactions [62]. Ophthalmate is a tripeptide analogue of glutathione and a useful biomarker of redox state and oxidative damage of tissues when it is accompanied typically by depletion of reduced glutathione (GSH) [63]. We found that lower levels of GSH were accompanied by a trend of higher levels of ophthalmate. Further, it is of interest to note that the glutathione cycle is also coupled with the GABA shunt (synthesis of $\gamma$-aminobutyrate) [64], thus changes in the levels of metabolites of glutathione cycle are likely to contribute to compound biochemical phenotypes.

The depressed levels of selective free fatty acids species and the accumulation of several acylcarnitine species in the brain of Ranbp $2^{+/-}$mice may result in part from changes in the limited free pool of CoA or intermediates thereof in the cytosol and mitochondria. Hence, we examined whether there were tissue differences in deficits of CoA in the liver, the major organ of CoA synthesis, the striatum, where the uptake and accumulation of $\mathrm{MPP}^{+}$takes place, and the midbrain, where a large number of dopaminergic cell bodies (e.g., substantia nigra) are clustered. We found the levels of CoA to be decreased over twofold in the striatum of Ranbp2 $2^{+/-}$mice, but not changed in the midbrain and liver (Fig. 10).

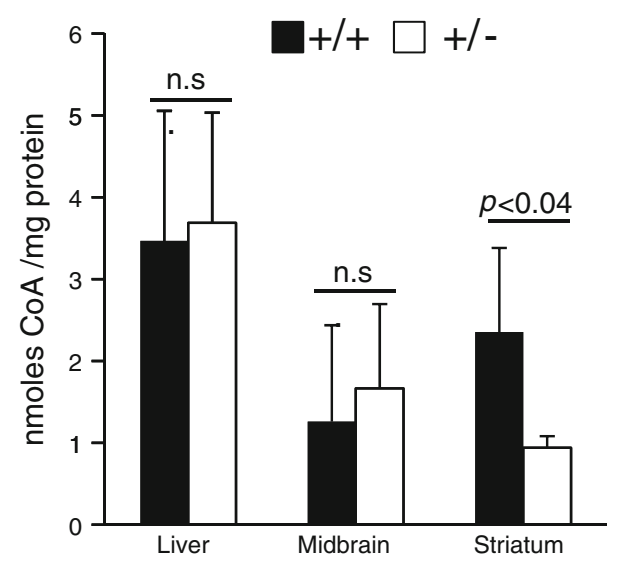

Fig. 10 Haploinsufficiency of Ranbp2 selectively causes a decrease of the levels of CoA in the striatum upon MPTP insult. CoA levels were decreased selectively in the striatum of $\operatorname{Ranbp} 2^{+/-}$mice relative to wild-type mice 6 days after the acute MPTP insult. No changes of CoA levels were observed in the midbrain and liver. Data shown represent the mean $\pm \mathrm{SD} ; n=4$, wild-type; $n=5$, Ranbp $2^{+/-}$. Black and white bars represent wild-type $(+/+)$ and Ranbp2 $2^{+/-}$ $(+/-)$ mice, respectively

\section{Discussion}

The data support that a difference in genetic dosage of Ranbp 2 in the inbred 129P2/OlaHsd genetic background modulates significant metabolic pathways in the brain without causing significant nigrostriatal cellular changes upon acute MPTP exposure. In contrast, a variety of cell types of the retina undergo significant cellular changes upon Ranbp 2 haploinsufficiency and MPTP exposure with the most striking effects observed by the suppression of the following cellular manifestations: (i) gliosis of $\mathrm{GFAP}^{+}$Müller cells outlasting the xenobiotic insult, (ii) recovery of $\mathrm{TH}^{+}$-amacrine neurons and (iii) activation of a heterogeneous population of proliferative cells across the retina. This study also uncovers a distinct and large proliferative population of cells elicited by MPTP that differ from those reported for other neurotoxicity models, such as intraocular injection of $N$-methyl-D-aspartic acid (NMDA) with or without selective growth factors, glutamate, or $\alpha$-aminoadipate [65-67]. NMDA together with retinoic acid induces the regeneration of a restricted number of Müller cells into bipolar or photoreceptor cells, whereas NMDA in the presence of EGF, FGF1, or FGF1 combined with insulin, stimulates the production of Müller glia with a small fraction of these regenerating into undefined amacrine neurons $[65,66]$. However, glutamate or $\alpha$-aminoadipate, which was found in this study to be significantly elevated in Ran$b p 2^{+/-}$, promotes the transient proliferation of Müller glial cells and differentiation into retinal neurons, such as photoreceptors [67]. By contrast, our study found that MPTP elicits long-lasting retinal gliosis by dramatically up-regulating resident $\mathrm{GFAP}^{+}$-Müller cells without the majority of these cells undergoing proliferation. Further, we did not identify any MPTP-elicited EdU ${ }^{+}$-proliferating cells with the capacity to regenerate into $\mathrm{TH}^{+}$-amacrine neurons even though most were localized to the inner retina. Instead, MPTP promotes the transient suppression of TH expression in dopaminergic amacrine neurons followed by marked and compensatory recoveries of $\mathrm{TH}$ expression in such neurons, a finding that is consistent with the work reported by Tatton et al. [25]. Hence, the data imply the existence of distinct cellular and molecular responses to MPTP-neurotoxicity between $\mathrm{TH}^{+}$-neurons of the brain and the retina. These data support the existence of distinct $\mathrm{TH}^{+}$-neuronal subtypes between these tissues and RanBP2- and microenvironmentdependent trophic signaling between unique populations of MPTP-activated and proliferative glia in the brain and retina.

These data also support the existence of a novel population of EdU ${ }^{+}$-proliferating cells elicited by MPTP and repressed by Ranbp 2 haploinsufficiency. In contrast to other inflammatory models of neurotoxicity and injury to the retina $[50-52,68]$, the EdU ${ }^{+}$-proliferating cells elicited 
by MPTP and resident in the retina were neither $\mathrm{CD} 45^{+}$ nor $\mathrm{CD}_{11 b^{+}}$and the former cells were never detected in retinas of Ranbp $2^{+/-}$mice. Instead, $\mathrm{CD} 45^{+} \mathrm{EdU}^{-}$and $\mathrm{CD} 45^{+} \mathrm{EdU}^{+}$cells were only detected in the choroid (vascular) plexus of Ranbp $2^{+/-}$mice, whereas $\mathrm{CD} 11 \mathrm{~b}^{+}$cells were exclusively present in the choroid plexus and they were all $\mathrm{EdU}^{-}$. Altogether, these data strengthen the notion of the development of distinct and antagonistic phenotypic outcomes observed between cell types by Ranbp2 insufficiency upon other disease stressors, such as phototoxicity [31, 32] and carcinogen exposure [34]. For example, the increased carcinogen-induced cellular proliferation (e.g., tumorigenesis) upon Ranbp2 insufficiency contrasts sharply with the suppression of the MPTP-induced proliferative capacity of progenitor cells in the retina of Ranbp $2^{+/-}$mice as uncovered by this study. These differences are likely caused by the deregulation of the Ranbp2-mediated nucleocytoplasmic shuttling of factors or receptors thereof controlling cell proliferation or differentiation [69-73]. One of such factors is the Ranbp2 partner, Ubc9, which is an E2ligase implicated in the shuttling and homeostasis of some orphan receptors [32, 74-78]. It is noteworthy that Ubc9 mediates the repression of pro-inflammatory responses in microglia and astrocytes by Nurr1 [79], which is associated with familial late-onset PD [80].

Our studies also reveal metabolic imbalances in the brain caused by haploinsufficiency of Ranbp 2 upon acute exposure to MPTP. The metabolic footprint uncovered is significant, because it not only validates and opens new venues to the identity of some undefined and possibly shared metabolites modulated by other stressors, such as phototoxicity [31, 32], but it also delineates disease and diagnostic predictors of metabolic pathways with relevance to the understanding of complex clinical and subclinical phenotypes of human diseases caused by interactions between the environment and Ranbp 2 .

In this regard, this study defines the identity of two medium-chains (pelargonate and caprate) and a long-chain fatty acid species (arachidate/eicosanoic acid), whose decreased levels are associated with haploinsufficiency of Ranbp2. Interestingly, the level of arachidate increases upon inflammation [81, 82] and as such, its decrease in Ranbp $2^{+/-}$ upon MPTP treatment may contribute to the suppression of inflammatory cellular responses observed in the retina of Ranbp $2^{+/-}$mice. Further, the modulation of pro-inflammatory responses linked to insufficiency of RanBP2 is likely mediated by the concerted action of multiple metabolites. 5 -methylthioadenosine and $\alpha$-aminoadipate, which are increased in Ranbp2 $2^{+/-}$mice, are additional metabolites with important anti-inflammatory or anti-proliferative properties, or both [67, 83, 84].

This work also identifies a set of metabolites from metabolic pathways, which are apparently distinct, and are known to either produce biomarkers of oxidative stress or present secondary and protective properties against toxic or injury insults of other etiologies. For example, L-propionyl carnitine is associated with a reduction in lipid hydroperoxides and superoxide anions and the propionyl moiety of $\mathrm{L}$ propionyl carnitine provides intermediates to the TCA cycle upon stress conditions and contributes to its therapeutic benefits [57]. Homocarnosine and 5-methylthioadenosine are also known to be protective against oxidative stress with the former acting also as a scavenger for reactive oxygen species [61, 83]. The increase of these metabolites is accompanied by disruption of redox homeostasis as reflected by an increase of diagnostic markers of oxidative stress, such as dehydroascorbate and ophthalmate, with the latter acting as biomarker of glutathione depletion [63]. Our data support that the rise of such "protective" metabolites likely represents secondary and compensatory responses and diagnostic markers to noxious insults and that insufficiency of RanBP2 confers an increased susceptibility to such neurotoxic damage in the brain.

Finally, the accumulation of various acyl-carnitines, glucose, lactic acid, and $\mathrm{NAD}^{+}$support a detoxifying efflux from the mitochondria of metabolites derived from the incomplete $\beta$-oxidation of free fatty acids concomitant with enhanced anaerobic glycolysis. Current knowledge supports that these imbalances arise likely from the glia, because neurons are thought not to utilize $\beta$-oxidation of free fatty acids as energy source [85]. These bioenergetic manifestations assume heightened relevance to our studies, because $\mathrm{MPP}^{+}$is thought to inhibit directly the NADH:ubiquinone oxidoreductase of Complex I of the electron transport chain of the mitochondria [6,7] and the decrease of the levels of CoA observed selectively in the striatum of Ranbp2 $2^{+/-}$ mice may contribute to the incomplete $\beta$-oxidation of free fatty acids in this brain region. It is not exactly clear how partial deficits of RanBP2 exacerbate certain bioenergetic facets of neurotoxic stress-induced manifestations. However, the work of Neilson et al. and ours support that the down-regulation of hexokinase I activity by deficits of RanBP2 [40] or stimulation of the uncoupling of state IV of oxidative phosphorylation by mutations in Ranbp2 upon infectious agents and febrile states $[33,86]$ may espouse a predilection for higher glucose levels and enhanced anaerobic glycolysis upon insufficiency of RanBP2 and exposure to a variety of stressors.

Collectively, these and other data point toward a number of RanBP2-mediated metabolic and neurodegenerative diseases of acute and insidious clinical expressions sharing strong gene-environment interactions and broader spectra of metabolic footprints and pathomechanisms than hitherto realized. For example, PD and acute encephalopathies often result in striatal injury, but differ by the onset or progression of injury. Familial necrotic encephalopathies 
caused by mutations in $R A N B P 2$ and a number of other encephalopathies of cerebral organic acid origin are often precipitated by episodes of febrile and infectious illnesses, which in turn may elicit fasting and catabolic stress, and secondarily, excitotoxic, and proinflammatory mechanisms [33, 87, 88]. Like other acute encephalopathies, infectious agents may also act as novel etiological agents in Parkinson disease [89, 90] and systemic metabolic deficits can directly promote dramatic clinical manifestations with distinct onsets and selective tissue expressions, such as age-dependent chorioretinal degenerations (e.g., gyrate atrophy) [91, 92], and once thought not to share pathomechanisms. In this regard, our findings strengthen the view that mouse models of Ranbp 2 are tractable genetic and physiological tools for the discovery of pathobiological mechanisms underlying diseases triggered by gene-environment interactions.

Acknowledgments We thank Drs. F. Haeseleer (University of Washington) and D. Pow (University of Queensland) for the antiCaBP5 and anti-GABA and anti-glycine antibodies, respectively. We thank Metabolon Inc. for providing a description of the mass spectrometry methodologies for specimen analyses. This work was supported by grants from the National Institutes of Health to PAF (EY019492, GM083165 and 2P30-EY005722) and Michael J. Fox Foundation. P.A.F. is the Jules \& Doris Stein Research to Prevent Blindness Professor.

Open Access This article is distributed under the terms of the Creative Commons Attribution License which permits any use, distribution, and reproduction in any medium, provided the original author(s) and the source are credited.

\section{References}

1. Heikkila RE, Hess A, Duvoisin RC (1984) Dopaminergic neurotoxicity of 1-methyl-4-phenyl-1,2,5,6-tetrahydropyridine in mice. Science 224:1451-1453

2. Dauer W, Przedborski S (2003) Parkinson's disease: mechanisms and models. Neuron 39:889-909

3. Dawson TM (2000) New animal models for Parkinson's disease. Cell 101:115-118

4. Kopin IJ, Markey SP (1988) MPTP toxicity: implications for research in Parkinson's disease. Annu Rev Neurosci 11:81-96

5. Javitch JA, D'Amato RJ, Strittmatter SM, Snyder SH (1985) Parkinsonism-inducing neurotoxin, $N$-methyl-4-phenyl-1,2,3,6tetrahydropyridine: uptake of the metabolite $N$-methyl-4-phenylpyridine by dopamine neurons explains selective toxicity. Proc Natl Acad Sci USA 82:2173-2177

6. Nicklas WJ, Vyas I, Heikkila RE (1985) Inhibition of NADHlinked oxidation in brain mitochondria by 1-methyl-4-phenylpyridine, a metabolite of the neurotoxin, 1-methyl-4-phenyl1,2,5,6-tetrahydropyridine. Life Sci 36:2503-2508

7. Ramsay RR, Salach JI, Singer TP (1986) Uptake of the neurotoxin 1-methyl-4-phenylpyridine (MPP+) by mitochondria and its relation to the inhibition of the mitochondrial oxidation of NAD+-linked substrates by MPP+. Biochem Biophys Res Commun 134:743-748
8. Lotharius J, O’Malley KL (2000) The parkinsonism-inducing drug 1-methyl-4-phenylpyridinium triggers intracellular dopamine oxidation. A novel mechanism of toxicity. J Biol Chem 275:38581-38588

9. Choi WS, Kruse SE, Palmiter RD, Xia Z (2008) Mitochondrial complex I inhibition is not required for dopaminergic neuron death induced by rotenone, MPP+, or paraquat. Proc Natl Acad Sci USA 105:15136-15141

10. Hasbani DM, Perez FA, Palmiter RD, O’Malley KL (2005) Dopamine depletion does not protect against acute 1-methyl-4phenyl-1,2,3,6-tetrahydropyridine toxicity in vivo. J Neurosci 25:9428-9433

11. Chen L, Ding Y, Cagniard B, Van Laar AD, Mortimer A, Chi W, Hastings TG, Kang UJ, Zhuang X (2008) Unregulated cytosolic dopamine causes neurodegeneration associated with oxidative stress in mice. J Neurosci 28:425-433

12. Pattarini R, Smeyne RJ, Morgan JI (2007) Temporal mRNA profiles of inflammatory mediators in the murine 1-methyl-4phenyl-1,2,3,6-tetrahydropyrimidine model of Parkinson's disease. Neuroscience 145:654-668

13. Wu DC, Jackson-Lewis V, Vila M, Tieu K, Teismann P, Vadseth C, Choi DK, Ischiropoulos H, Przedborski S (2002) Blockade of microglial activation is neuroprotective in the 1-methyl-4-phenyl1,2,3,6-tetrahydropyridine mouse model of Parkinson disease. J Neurosci 22:1763-1771

14. Adams JD Jr, Kalivas PW, Miller CA (1989) The acute histopathology of MPTP in the mouse CNS. Brain Res Bull 23:1-17

15. Sedelis M, Schwarting RK, Huston JP (2001) Behavioral phenotyping of the MPTP mouse model of Parkinson's disease. Behav Brain Res 125:109-125

16. Sedelis M, Hofele K, Auburger GW, Morgan S, Huston JP, Schwarting RK (2000) MPTP susceptibility in the mouse: behavioral, neurochemical, and histological analysis of gender and strain differences. Behav Genet 30:171-182

17. Gibrat C, Saint-Pierre M, Bousquet M, Levesque D, Rouillard C, Cicchetti F (2009) Differences between subacute and chronic MPTP mice models: investigation of dopaminergic neuronal degeneration and alpha-synuclein inclusions. J Neurochem 109:1469-1482

18. Fornai F, Schluter OM, Lenzi P, Gesi M, Ruffoli R, Ferrucci M, Lazzeri G, Busceti CL, Pontarelli F, Battaglia G, Pellegrini A, Nicoletti F, Ruggieri S, Paparelli A, Sudhof TC (2005) Parkinson-like syndrome induced by continuous MPTP infusion: convergent roles of the ubiquitin-proteasome system and alphasynuclein. Proc Natl Acad Sci USA 102:3413-3418

19. Smeyne M, Jiao Y, Shepherd KR, Smeyne RJ (2005) Glia cell number modulates sensitivity to MPTP in mice. Glia 52:144-152

20. Hamre K, Tharp R, Poon K, Xiong X, Smeyne RJ (1999) Differential strain susceptibility following 1-methyl-4-phenyl1,2,3,6-tetrahydropyridine (MPTP) administration acts in an autosomal dominant fashion: quantitative analysis in seven strains of Mus musculus. Brain Res 828:91-103

21. Masland RH (2001) The fundamental plan of the retina. Nat Neurosci 4:877-886

22. Masland RH, Rizzo JF 3rd, Sandell JH (1993) Developmental variation in the structure of the retina. J Neurosci 13:5194-5202

23. Witkovsky P (2004) Dopamine and retinal function. Doc Ophthalmol 108:17-40

24. Archibald NK, Clarke MP, Mosimann UP, Burn DJ (2009) The retina in Parkinson's disease. Brain 132:1128-1145

25. Tatton WG, Kwan MM, Verrier MC, Seniuk NA, Theriault E (1990) MPTP produces reversible disappearance of tyrosine hydroxylase-containing retinal amacrine cells. Brain Res 527:21-31

26. Nagel F, Bahr M, Dietz GP (2009) Tyrosine hydroxylase-positive amacrine interneurons in the mouse retina are resistant against the 
application of various parkinsonian toxins. Brain Res Bull 79:303-309

27. Harnois C, Marcotte G, Daigle M, Di Paolo T (1989) Retinal dopamine sensitivity to MPP+ toxicity: electrophysiological and biochemical evaluation. Neurosci Lett 107:19-25

28. Takatsuna Y, Adachi-Usami E, Ino H, Chiba T (1992) Effects of MPTP on the mouse retina. Nippon Ganka Gakkai Zasshi 96:767-775

29. Cuenca N, Herrero MT, Angulo A, de Juan E, Martinez-Navarrete GC, Lopez S, Barcia C, Martin-Nieto J (2005) Morphological impairments in retinal neurons of the scotopic visual pathway in a monkey model of Parkinson's disease. J Comp Neurol 493:261-273

30. Chen ST, Hsu JR, Hsu PC, Chuang JI (2003) The retina as a novel in vivo model for studying the role of molecules of the Bcl-2 family in relation to MPTP neurotoxicity. Neurochem Res 28:805-814

31. Cho KI, Yi H, Yeh A, Tserentsoodol N, Cuadrado L, Searle K, Hao Y, Ferreira PA (2009) Haploinsufficiency of RanBP2 is neuroprotective against light-elicited and age-dependent degeneration of photoreceptor neurons. Cell Death Differ 16:287-297

32. Cho KI, Yi H, Tserentsoodol N, Searle K, Ferreira PA (2010) Neuroprotection resulting from insufficiency of RANBP2 is associated with the modulation of protein and lipid homeostasis of functionally diverse but linked pathways in response to oxidative stress. Dis Model Mech 3:595-604

33. Neilson DE, Adams MD, Orr CM, Schelling DK, Eiben RM, Kerr DS, Anderson J, Bassuk AG, Bye AM, Childs AM, Clarke A, Crow YJ, Di Rocco M, Dohna-Schwake C, Dueckers G, Fasano AE, Gika AD, Gionnis D, Gorman MP, Grattan-Smith PJ, Hackenberg A, Kuster A, Lentschig MG, Lopez-Laso E, Marco EJ, Mastroyianni S, Perrier J, Schmitt-Mechelke T, Servidei S, Skardoutsou A, Uldall P, van der Knaap MS, Goglin KC, Tefft DL, Aubin C, de Jager P, Hafler D, Warman ML (2009) Infection-triggered familial or recurrent cases of acute necrotizing encephalopathy caused by mutations in a component of the nuclear pore, RANBP2. Am J Hum Genet 84:44-51

34. Dawlaty MM, Malureanu L, Jeganathan KB, Kao E, Sustmann C, Tahk S, Shuai K, Grosschedl R, van Deursen JM (2008) Resolution of sister centromeres requires RanBP2-mediated SUMOylation of topoisomerase IIalpha. Cell 133:103-115

35. Um JW, Min DS, Rhim H, Kim J, Paik SR, Chung KC (2006) Parkin ubiquitinates and promotes the degradation of RanBP2. J Biol Chem 281:3595-3603

36. Veeriah S, Taylor BS, Meng S, Fang F, Yilmaz E, Vivanco I, Janakiraman M, Schultz N, Hanrahan AJ, Pao W, Ladanyi M, Sander C, Heguy A, Holland EC, Paty PB, Mischel PS, Liau L, Cloughesy TF, Mellinghoff IK, Solit DB, Chan TA (2010) Somatic mutations of the Parkinson's disease-associated gene PARK2 in glioblastoma and other human malignancies. Nat Genet 42:77-82

37. Shimura H, Hattori N, Kubo S, Mizuno Y, Asakawa S, Minoshima S, Shimizu N, Iwai K, Chiba T, Tanaka K, Suzuki T (2000) Familial Parkinson disease gene product, parkin, is a ubiquitinprotein ligase. Nat Genet 25:302-305

38. Pichler A, Gast A, Seeler JS, Dejean A, Melchior F (2002) The nucleoporin RanBP2 has SUMO1 E3 ligase activity. Cell 108:109-120

39. Cho KI, Cai Y, Yi H, Yeh A, Aslanukov A, Ferreira PA (2007) Association of the kinesin-binding domain of RanBP2 to KIF5B and KIF5C determines mitochondria localization and function. Traffic 8:1722-1735

40. Aslanukov A, Bhowmick R, Guruju M, Oswald J, Raz D, Bush RA, Sieving PA, Lu X, Bock CB, Ferreira PA (2006) RanBP2 modulates Cox11 and Hexokinase I activities and haploinsufficiency of RanBP2 causes deficits in glucose metabolism. PLoS Genet 2:e177
41. Darios F, Corti O, Lucking CB, Hampe C, Muriel MP, Abbas N, Gu WJ, Hirsch EC, Rooney T, Ruberg M, Brice A (2003) Parkin prevents mitochondrial swelling and cytochrome $\mathrm{c}$ release in mitochondria-dependent cell death. Hum Mol Genet 12:517-526

42. Palacino JJ, Sagi D, Goldberg MS, Krauss S, Motz C, Wacker M, Klose J, Shen J (2004) Mitochondrial dysfunction and oxidative damage in parkin-deficient mice. J Biol Chem 279:18614-18622

43. Kim KY, Stevens MV, Akter MH, Rusk SE, Huang RJ, Cohen A, Noguchi A, Springer D, Bocharov AV, Eggerman TL, Suen DF, Youle RJ, Amar M, Remaley AT, Sack MN (2011) Parkin is a lipid-responsive regulator of fat uptake in mice and mutant human cells. J Clin Invest 121:3701-3712

44. Arai Y, Pulvers JN, Haffner C, Schilling B, Nusslein I, Calegari F, Huttner WB (2011) Neural stem and progenitor cells shorten $\mathrm{S}$-phase on commitment to neuron production. Nat Commun 2:154

45. Kreutzberg GW (1996) Microglia: a sensor for pathological events in the CNS. Trends Neurosci 19:312-318

46. Jadhav AP, Roesch K, Cepko CL (2009) Development and neurogenic potential of Muller glial cells in the vertebrate retina. Prog Retin Eye Res 28:249-262

47. Taranova OV, Magness ST, Fagan BM, Wu Y, Surzenko N, Hutton SR, Pevny LH (2006) SOX2 is a dose-dependent regulator of retinal neural progenitor competence. Genes Dev 20:1187-1202

48. Gonzalez-Scarano F, Baltuch G (1999) Microglia as mediators of inflammatory and degenerative diseases. Annu Rev Neurosci 22:219-240

49. Hickey WF, Kimura H (1988) Perivascular microglial cells of the CNS are bone marrow-derived and present antigen in vivo. Science 239:290-292

50. Xu H, Dawson R, Forrester JV, Liversidge J (2007) Identification of novel dendritic cell populations in normal mouse retina. Invest Ophthalmol Vis Sci 48:1701-1710

51. Nakazawa T, Hisatomi T, Nakazawa C, Noda K, Maruyama K, She H, Matsubara A, Miyahara S, Nakao S, Yin Y, Benowitz L, Hafezi-Moghadam A, Miller JW (2007) Monocyte chemoattractant protein 1 mediates retinal detachment-induced photoreceptor apoptosis. Proc Natl Acad Sci USA 104:2425-2430

52. Lehmann U, Heuss ND, McPherson SW, Roehrich H, Gregerson DS (2010) Dendritic cells are early responders to retinal injury. Neurobiol Dis 40:177-184

53. Bjorkhem I, Miettinen T, Reihner E, Ewerth S, Angelin B, Einarsson K (1987) Correlation between serum levels of some cholesterol precursors and activity of HMG-CoA reductase in human liver. J Lipid Res 28:1137-1143

54. Kempen HJ, Glatz JF, Gevers Leuven JA, van der Voort HA, Katan MB (1988) Serum lathosterol concentration is an indicator of whole-body cholesterol synthesis in humans. J Lipid Res 29:1149-1155

55. Robishaw JD, Neely JR (1985) Coenzyme A metabolism. Am J Physiol 248:E1-E9

56. Koves TR, Ussher JR, Noland RC, Slentz D, Mosedale M, Ilkayeva O, Bain J, Stevens R, Dyck JR, Newgard CB, Lopaschuk GD, Muoio DM (2008) Mitochondrial overload and incomplete fatty acid oxidation contribute to skeletal muscle insulin resistance. Cell Metab 7:45-56

57. Ramsay RR, Zammit VA (2004) Carnitine acyltransferases and their influence on CoA pools in health and disease. Mol Aspects Med 25:475-493

58. Owen OE, Kalhan SC, Hanson RW (2002) The key role of anaplerosis and cataplerosis for citric acid cycle function. J Biol Chem 277:30409-30412

59. Lang F (2007) Mechanisms and significance of cell volume regulation. J Am Coll Nutr 26:613S-623S 
60. Benarroch EE (2010) Histamine in the CNS: multiple functions and potential neurologic implications. Neurology 75:1472-1479

61. De Marchis S, Modena C, Peretto P, Migheli A, Margolis FL, Fasolo A (2000) Carnosine-related dipeptides in neurons and glia. Biochemistry (Mosc) 65:824-833

62. Bairaktari E, Katopodis K, Siamopoulos KC, Tsolas O (1998) Paraquat-induced renal injury studied by $1 \mathrm{H}$ nuclear magnetic resonance spectroscopy of urine. Clin Chem 44:1256-1261

63. Soga T, Baran R, Suematsu M, Ueno Y, Ikeda S, Sakurakawa T, Kakazu Y, Ishikawa T, Robert M, Nishioka T, Tomita M (2006) Differential metabolomics reveals ophthalmic acid as an oxidative stress biomarker indicating hepatic glutathione consumption. J Biol Chem 281:16768-16776

64. Weber GF (1999) Final common pathways in neurodegenerative diseases: regulatory role of the glutathione cycle. Neurosci Biobehav Rev 23:1079-1086

65. Karl MO, Hayes S, Nelson BR, Tan K, Buckingham B, Reh TA (2008) Stimulation of neural regeneration in the mouse retina. Proc Natl Acad Sci USA 105:19508-19513

66. Ooto S, Akagi T, Kageyama R, Akita J, Mandai M, Honda Y, Takahashi M (2004) Potential for neural regeneration after neurotoxic injury in the adult mammalian retina. Proc Natl Acad Sci USA 101:13654-13659

67. Takeda M, Takamiya A, Jiao JW, Cho KS, Trevino SG, Matsuda $\mathrm{T}$, Chen DF (2008) $\alpha$-Aminoadipate induces progenitor cell properties of Muller glia in adult mice. Invest Ophthalmol Vis Sci 49:1142-1150

68. London A, Itskovich E, Benhar I, Kalchenko V, Mack M, Jung S, Schwartz M (2011) Neuroprotection and progenitor cell renewal in the injured adult murine retina requires healing monocytederived macrophages. J Exp Med 208:23-39

69. Delphin C, Guan T, Melchior F, Gerace L (1997) RanGTP targets p97 to RanBP2, a filamentous protein localized at the cytoplasmic periphery of the nuclear pore complex. Mol Biol Cell 8:2379-2390

70. Singh BB, Patel HH, Roepman R, Schick D, Ferreira PA (1999) The zinc finger cluster domain of RanBP2 is a specific docking site for the nuclear export factor, exportin-1. J Biol Chem 274:37370-37378

71. Vetter IR, Nowak C, Nishimoto T, Kuhlmann J, Wittinghofer A (1999) Structure of a Ran-binding domain complexed with Ran bound to a GTP analogue: implications for nuclear transport. Nature 398:39-46

72. Bernad R, van der Velde H, Fornerod M, Pickersgill H (2004) Nup358/RanBP2 attaches to the nuclear pore complex via association with Nup88 and Nup214/CAN and plays a supporting role in CRM1-mediated nuclear protein export. Mol Cell Biol 24:2373-2384

73. Forler D, Rabut G, Ciccarelli FD, Herold A, Kocher T, Niggeweg R, Bork P, Ellenberg J, Izaurralde E (2004) RanBP2/Nup358 provides a major binding site for NXF1-p15 dimers at the nuclear pore complex and functions in nuclear mRNA export. Mol Cell Biol 24:1155-1167

74. Chakrabarti SR, Sood R, Ganguly S, Bohlander S, Shen Z, Nucifora G (1999) Modulation of TEL transcription activity by interaction with the ubiquitin-conjugating enzyme UBC9. Proc Natl Acad Sci USA 96:7467-7472

75. Poukka H, Aarnisalo P, Karvonen U, Palvimo JJ, Janne OA (1999) Ubc9 interacts with the androgen receptor and activates receptor-dependent transcription. J Biol Chem 274:19441-19446

76. Kurtzman AL, Schechter N (2001) Ubc9 interacts with a nuclear localization signal and mediates nuclear localization of the paired-like homeobox protein Vsx-1 independent of SUMO-1 modification. Proc Natl Acad Sci USA 98:5602-5607
77. Kobayashi S, Shibata H, Kurihara I, Yokota K, Suda N, Saito I, Saruta T (2004) Ubc9 interacts with chicken ovalbumin upstream promoter-transcription factor I and represses receptor-dependent transcription. J Mol Endocrinol 32:69-86

78. Kurihara I, Shibata H, Kobayashi S, Suda N, Ikeda Y, Yokota K, Murai A, Saito I, Rainey WE, Saruta T (2005) Ubc9 and protein inhibitor of activated STAT 1 activate chicken ovalbumin upstream promoter-transcription factor I-mediated human CYP11B2 gene transcription. J Biol Chem 280:6721-6730

79. Saijo K, Winner B, Carson CT, Collier JG, Boyer L, Rosenfeld MG, Gage FH, Glass CK (2009) A Nurr1/CoREST pathway in microglia and astrocytes protects dopaminergic neurons from inflammation-induced death. Cell 137:47-59

80. Le WD, Xu P, Jankovic J, Jiang H, Appel SH, Smith RG, Vassilatis DK (2003) Mutations in NR4A2 associated with familial Parkinson disease. Nat Genet 33:85-89

81. Ma K, Langenbach R, Rapoport SI, Basselin M (2007) Altered brain lipid composition in cyclooxygenase- 2 knockout mouse. J Lipid Res 48:848-854

82. Boyd JD, Jang H, Shepherd KR, Faherty C, Slack S, Jiao Y, Smeyne RJ (2007) Response to 1-methyl-4-phenyl-1,2,3,6-tetrahydropyridine (MPTP) differs in mouse strains and reveals a divergence in JNK signaling and COX-2 induction prior to loss of neurons in the substantia nigra pars compacta. Brain Res 1175:107-116

83. Avila MA, Garcia-Trevijano ER, Lu SC, Corrales FJ, Mato JM (2004) Methylthioadenosine. Int $\mathrm{J}$ Biochem Cell Biol 36:2125-2130

84. Chen L, Zeng Y, Yang H, Lee TD, French SW, Corrales FJ, Garcia-Trevijano ER, Avila MA, Mato JM, Lu SC (2004) Impaired liver regeneration in mice lacking methionine adenosyltransferase 1A. FASEB J 18:914-916

85. Speijer D (2010) Oxygen radicals shaping evolution: why fatty acid catabolism leads to peroxisomes while neurons do without it: FADH/NADH flux ratios determining mitochondrial radical formation were crucial for the eukaryotic invention of peroxisomes and catabolic tissue differentiation. BioEssays 33:88-94

86. Neilson DE, Eiben RM, Waniewski S, Hoppel CL, Varnes ME, Bangert BA, Wiznitzer M, Warman ML, Kerr DS (2003) Autosomal dominant acute necrotizing encephalopathy. Neurology 61:226-230

87. Gordon N (2006) Glutaric aciduria types I and II. Brain Dev 28:136-140

88. Zinnanti WJ, Lazovic J, Housman C, LaNoue K, O'Callaghan JP, Simpson I, Woontner M, Goodman SI, Connor JR, Jacobs RE, Cheng KC (2007) Mechanism of age-dependent susceptibility and novel treatment strategy in glutaric acidemia type I. J Clin Invest 117:3258-3270

89. Jang H, Boltz DA, Webster RG, Smeyne RJ (2009) Viral parkinsonism. Biochim Biophys Acta 1792:714-721

90. Jang H, Boltz D, Sturm-Ramirez K, Shepherd KR, Jiao Y, Webster R, Smeyne RJ (2009) Highly pathogenic H5N1 influenza virus can enter the central nervous system and induce neuroinflammation and neurodegeneration. Proc Natl Acad Sci USA 106:14063-14068

91. Wang T, Lawler AM, Steel G, Sipila I, Milam AH, Valle D (1995) Mice lacking ornithine-delta-aminotransferase have paradoxical neonatal hypoornithinaemia and retinal degeneration. Nat Genet 11:185-190

92. Wang T, Milam AH, Steel G, Valle D (1996) A mouse model of gyrate atrophy of the choroid and retina. Early retinal pigment epithelium damage and progressive retinal degeneration. J Clin Invest 97:2753-2762 